\title{
Effect of land cover on atmospheric processes and air quality over the continental United States - a NASA Unified WRF (NU-WRF) model study
}

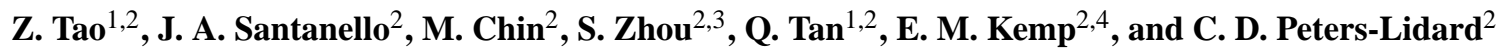 \\ ${ }^{1}$ Universities Space Research Association, 10211 Wincopin Circle, Columbia, MD 21044, USA \\ ${ }^{2}$ NASA Goddard Space Flight Center, Greenbelt, MD 20771, USA \\ ${ }^{3}$ Northrop Grumman Information System, McLean, VA 22102, USA \\ ${ }^{4}$ Science System and Applications, Inc., Lanham, MD 20706, USA \\ Correspondence to: Z. Tao (zhining.tao@nasa.gov)
}

Received: 20 December 2012 - Published in Atmos. Chem. Phys. Discuss.: 27 February 2013

Revised: 24 May 2013 - Accepted: 28 May 2013 - Published: 1 July 2013

\begin{abstract}
The land surface plays a crucial role in regulating water and energy fluxes at the land-atmosphere ( $\mathrm{L}-\mathrm{A})$ interface and controls many processes and feedbacks in the climate system. Land cover and vegetation type remains one key determinant of soil moisture content that impacts air temperature, planetary boundary layer (PBL) evolution, and precipitation through soil-moisture-evapotranspiration coupling. In turn, it will affect atmospheric chemistry and air quality. This paper presents the results of a modeling study of the effect of land cover on some key L-A processes with a focus on air quality. The newly developed NASA Unified Weather Research and Forecast (NU-WRF) modeling system couples NASA's Land Information System (LIS) with the community WRF model and allows users to explore the LA processes and feedbacks. Three commonly used satellitederived land cover datasets - i.e., from the US Geological Survey (USGS) and University of Maryland (UMD), which are based on the Advanced Very High Resolution Radiometer (AVHRR), and from the Moderate Resolution Imaging Spectroradiometer (MODIS) - bear large differences in agriculture, forest, grassland, and urban spatial distributions in the continental United States, and thus provide an excellent case to investigate how land cover change would impact atmospheric processes and air quality. The weeklong simulations demonstrate the noticeable differences in soil moisture/temperature, latent/sensible heat flux, PBL height, wind, $\mathrm{NO}_{2}$ /ozone, and $\mathrm{PM}_{2.5}$ air quality. These discrepancies can be traced to associate with the land cover properties, e.g.,
\end{abstract}

stomatal resistance, albedo and emissivity, and roughness characteristics. It also implies that the rapid urban growth may have complex air quality implications with reductions in peak ozone but more frequent high ozone events.

\section{Introduction}

Land surface processes exert a profound impact on the overlaying atmosphere through a series of "chain processes", which links soil moisture (SM) to plant evapotranspiration (ET) to planetary boundary layer (PBL) evolution and water/energy flux entrainment, as well as to cloud/precipitation development (e.g., Sun and Bosilovich, 1996; Seneviratne et al., 2010), whereby the physical characteristics of land use and land cover (LULC) regulate moisture and energy exchanges between the land and the atmosphere (L-A). For example, land surface emissivity, which is the ratio of energy emitted from land to that from an ideal blackbody at the same temperature, is used to calculate the upward longwave radiation from the land surface following the StefanBoltzmann law (e.g., Jin and Liang, 2006). The closer to a value of 1 the emissivity, the better the land as an emitter. Terrestrial albedo, or reflection coefficient, denotes for the ability of land surface to reflect the incoming short-wave solar radiation into the atmosphere, which is also important to modeling the land surface energy balance. The larger the albedo, the less energy the land surface absorbs. Leaf area 
index (LAI) impacts the partition of surface heat fluxes and regulates light extinction within the canopy that directly affects the leaf stomatal conductance. LAI and stomatal resistance (RS) parameters are required to estimate the canopy resistance, which, together with the green vegetation fraction (SHDFAC), is subsequently used to calculate plant ET (Seneviratne et al., 2010; Kumar et al., 2011) that determines the water cycle in the land-biosphere-atmosphere system. Generally, the canopy resistance is positively proportional to RS but negatively to LAI. Large canopy resistance leads to small ET (Kumar et al., 2011) and slows dry deposition of an atmospheric species (Charusombat et al., 2010). Surface roughness length $(Z 0)$ parameterizes the roughness characteristics of the terrain and affects the intensity of mechanical turbulence and fluxes of various quantities above the surface. Urban and forest LULCs bear high $Z 0$ values that tend to reduce the near-surface wind speed.

Since the pioneering work by Deardorff (1978), who developed the first detailed parameterization of the land surface that was efficient enough to be applied in the atmospheric numerical simulation, many studies have been carried out to investigate the land surface effect on boundary layer meteorology and, more recently, on air quality. For example, Sun and Bosilovich (1996) examined the sensitivity of boundary layer meteorology to the selection of land surface parameters - e.g., vegetation cover, minimum RS, Z0, and initial $\mathrm{SM}$ - and found out that the SM gave the largest impact on the PBL height (PBLH) and surface heat budget. Kohler et al. (2010) studied the impact of SM on boundary layer characteristics - e.g., temperature and PBLH - using the observations from the African Monsoon Multidisciplinary Analysis (AMMA) campaign. Santanello et al. (2011) used a "process chain" to describe how SM affected the precipitation. Cheng et al. (2008) demonstrated that the accurate representation of land surface properties was crucial to modeling the realistic meteorology and air quality with a model study focused on the Houston-Galveston metropolitan areas. Ganzeveld et al. (2010) investigated the impacts of LULC changes on atmospheric chemistry at a global scale and found that the overall influence on reactive trace-gas exchanges was not very large due to the compensation effects; for example, the reduction in soil $\mathrm{NO}$ emissions from tropical forest clearing was made up for by a decrease in $\mathrm{NO}_{2}$ foliage uptake.

Though impacts of the land surface on PBL and chemistry processes have been demonstrated in these studies, the practical issue of how to best represent these processes in coupled models remains unresolved. In particular, the vast arrays of land surface schemes often use different land cover datasets that are applied at different spatial resolutions. This makes intercomparison across different models or even within models of different versions and datasets untenable. This issue will only grow in importance as the number of satellitederived datasets continues to increase along with the model complexity. To this end, this study addresses the LULC impacts on atmospheric processes and air quality from a differ- ent perspective. Instead of arbitrarily adjusting land surface parameters or relying on models to project LULC changes, this study employs three widely used and observation-driven LULC datasets within one modeling system. These three datasets are from the US Geological Survey (USGS, Loveland et al., 2000) and University of Maryland (UMD, Hansen et al., 2000), which are based on the Advanced Very High Resolution Radiometer (AVHRR), and from the Moderate Resolution Imaging Spectroradiometer (MODIS, Friedl et al., 2002). They display a large discrepancy in LULC classification and distribution, and provide an excellent proxy case to investigate how LULC and its change would affect the atmospheric chemistry. The newly developed NASA Unified Weather Research and Forecasting (NU-WRF) modeling system is used to explore this, utilizing the flexible land surface model (LSM) interface of NASA's Land Information System (LIS, Kumar et al., 2006; Peters-Lidard et al., 2007).

The paper presents the model, LULC data, and experimental design details in Sect. 2. Section 3 then follows with results of the most relevant parameters (e.g., SM, surface temperature, wind, and PBLH), followed by the analysis of the land surface emissions, dry deposition, and air quality focusing on ozone chemistry. Lastly, the implication of urbanization to air quality is briefly discussed, followed by the summary and conclusions.

\section{NU-WRF modeling system and evaluation}

\subsection{Model description}

NU-WRF was developed from the advanced research version of WRF (Michalakes et al., 2001) and WRF-Chem (Grell et al., 2005). Inheriting all the WRF features - e.g., Eulerian mass dynamic core, and 2-way nesting and physics - NUWRF incorporates NASA's unique experience and capabilities by fully integrating the LIS, the Goddard radiation (Chou and Suares, 1999) and microphysics (Shi et al., 2010; Tao et al., 2011) schemes, and the Goddard Chemistry Aerosol Radiation and Transport (GOCART) model (Chin et al., 2002) into a single modeling framework. In addition, it links to the Goddard Satellite Data Simulator Unit (G-SDSU, Matsui et al., 2009), allowing the conversion of modeled parameters to radiance and backscattering that can directly be compared with the satellite level-1 measurements at a relevant spatial and temporal scale. Overall, NU-WRF provides the modeling community with an observation-driven integrated system that represents aerosol/chemistry, cloud, precipitation, and land processes at satellite-resolved scales (roughly $1-25 \mathrm{~km}$ ).

LIS is a software framework that drives a suite of land surface models (LSMs) with satellite/ground-based observations and model reanalysis data. It provides a flexible and satellite-based high-resolution representation of land surface physics and states (e.g., soil and vegetation), which are directly coupled to the atmosphere. It can spin-up land surface 
conditions on a common grid to initialize NU-WRF, and allow various plug-ins such as land data assimilation, parameter estimation, and uncertainty analysis (Santanello et al., 2011, 2013). LIS can be run both in offline and coupled mode for NU-WRF. The major advantages of this modeling arrangement are multifold (Kumar et al., 2008). First, LIS is capable of conducting a long-term offline "spin-up" to allow the land surface and soil profiles to reach thermodynamic equilibrium, which otherwise is impossible in WRF. The initial soil conditions rendered by this long-term offline LIS spin-up resulted in an improved simulation of timing and evolution of a sea-breeze circulation over portions of northwestern Florida (Case et al., 2008). Case et al. (2011) also investigated the impact of a LIS spin-up on summertime precipitation over the southeastern US. They found that the nearsurface SM was improved in the spin-up, and that there was measurable impact of the spin-up on the coupled near-surface and PBL conditions relative to that using the default land initialization via WRF. Second, the offline LIS can be run using the same LSM and at the same resolution as the online version, thus making the data internally consistent and eliminating the need for horizontal spatial interpolation. Last but not the least, the LIS framework allows users to introduce new ancillary datasets (e.g., land cover, soil type, vegetation condition) into NU-WRF, which makes this study possible.

\subsection{Experimental design and model set-up}

Three sets of NU-WRF simulations have been carried out with the identical physics, gas and aerosol chemistry, emissions, and meteorological and chemical lateral boundary conditions but different LULC representation. The key common options for NU-WRF modeling are the Goddard microphysics and the long/short-wave radiation scheme, LIS as the land surface component (Kumar et al., 2008), the MoninObukhov surface layer scheme, the Yonsei University planetary boundary layer scheme (YSU, Hong et al., 2006), the new Grell cumulus scheme - an improved Grell-Devenyi ensemble cumulus scheme (Grell and Devenyi, 2002) that allows subsidence spreading for high-resolution simulation (Lin et al., 2010), the second generation regional acid deposition model (RADM2, Stockwell et al., 1990; Gross and Stockwell, 2003) gas-phase chemical mechanism, and the GOCART aerosol scheme. Over a multiyear spin-up, LIS generates the physical states of soil moisture and soil temperature that are then fed into NU-WRF as the initial land surface conditions. The LIS spin-up improves upon common approaches of employing coarse atmospheric data initialization of the land surface and of using a "cold-start" initial condition.

To investigate the effect of LULC on atmospheric processes and air quality, three commonly used LULC datasets from USGS, UMD, and MODIS have been applied within the LIS framework to the Noah LSM (Ek et al., 2003) version 3.2 with the corresponding NU-WRF experiments designated as E_USGS, E_UMD, and E_MODIS, respectively.

Within the Noah LSM, the State Soil Geographic (STATSGO, Miller and White, 1998) soil texture database, along with the three LULC datasets, were applied. The atmospheric forcing data for the spin-up period were provided by the North American Land Data Assimilation System (NLDAS, Mitchell et al., 2004). Rodell et al. (2005) examined the sensitivity (and in turn, requirements) of equilibration to the length of the spin-up run, which was found to vary with different climate regimes (e.g., cold and dry regions tended to take longer to equilibrate than warm and moist locales) and soil type, but that a 3-4 yr spin-up was sufficient in most cases. Case et al. (2008), who applied LIS-WRF to weather forecast, found that a $2 \mathrm{yr}$ offline spin-up was warranted to ensure convergence to a soil state equilibrium. Following the findings, the offline LIS was run for $3.5 \mathrm{yr}$ leading to 26 May 2010. The output from the LIS spin-up was then used to initialize soil temperature and soil moisture in NU-WRF simulations. In the coupled simulation, the NU-WRF-generated atmospheric forcing variables drove the Noah LSM within LIS to produce surface energy and water fluxes that were fed back into NU-WRF at each time step. In this manner, a consistent LSM configuration was employed in both NU-WRF and offline LIS.

Anthropogenic emissions in this study were from the 2005 National Emissions Inventory compiled by the US Environmental Protection Agency (http://www.epa.gov/ttnchie1/ net/2005inventory.html, USEPA). Fire emissions were from the Global Fire Data version 3 (GFED3, van der Werf et al., 2010; $\mathrm{Mu}$ et al., 2011). Biogenic emissions were calculated online using the Model of Emissions of Gases and Aerosols from Nature version 2 (MEGAN2, Guenther et al., 2006). Dust emissions were estimated online based on the surface wind speed, soil moisture, and soil erodibility map that was originally generated for global model GOCART (Ginoux et al., 2001) and updated with higher spatial resolution $\left(0.25^{\circ} \times 0.25^{\circ}\right)$.

The NU-WRF domain centered over the contiguous US (CONUS) with a horizontal spatial resolution of $20 \mathrm{~km}$. In all, there were $245 \times 163$ horizontal grid cells, and 40 vertical levels extending from surface to $50 \mathrm{mb}$. The meteorological initial and lateral boundary conditions (LBC) were derived from the $6 \mathrm{~h}$ Final (FNL) Operational Global Analysis data by the National Centers for Environmental Prediction (NCEP). The chemical LBC was based on the $6 \mathrm{~h}$ results from the Model for Ozone And Related chemical Tracers (MOZART, Emmons et al., 2010). The simulation period was from 26 May to 3 June 2010, and the analysis was based on the final 5-day simulation (30 May-3 June) allowing 3 days for the model spin-up (26-29 May) following the recommendation by Berge et al. (2001), who pointed out that local emissions and meteorology would take control and the uncertainties in initial conditions would have a minimal impact on air quality simulation after the 3-day spin-up. 
Table 1. Percentage agreements of MODIS/USGS, MODIS/UMD, and USGS/UMD for eight common land classifications.

\begin{tabular}{lccc}
\hline Land Category & MODIS and USGS (\%) & MODIS and UMD (\%) & USGS and UMD (\%) \\
\hline Evergreen Needleleaf Forest & 76.2 & 62.3 & 46.3 \\
Evergreen Broadleaf Forest & 0.3 & 9.6 & 3.1 \\
Deciduous Broadleaf Forest & 67.3 & 56.9 & 38.3 \\
Mixed Forests & 51.3 & 37.5 & 34.5 \\
Barren or Sparsely Vegetated & 42.0 & 63.9 & 91.3 \\
Grasslands & 43.4 & 47.0 & 57.0 \\
Urban and Built-up Land & 36.7 & 44.3 & 96.3 \\
Croplands & 64.3 & 72.1 & 53.3 \\
\hline
\end{tabular}

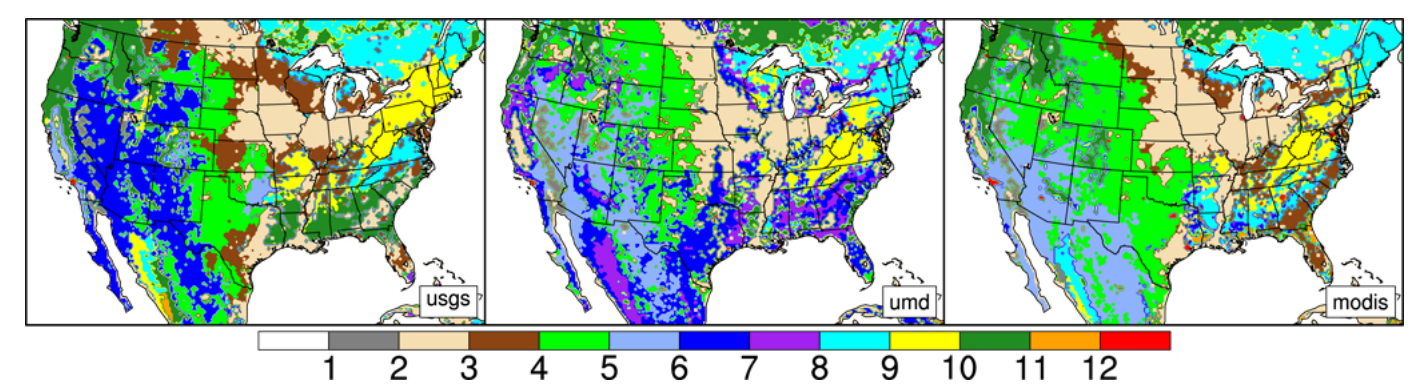

Fig. 1. LULC maps from USGS, UMD, and MODIS. 1 (grey) represents barren or sparsely vegetated land; 2, croplands; 3 , cropland/natural land mosaic; 4, grasslands; 5, open shrubland; 6, closed shrubland; 7, woodland; 8, mixed forests; 9, deciduous broadleaf forest; 10, evergreen needleleaf forest; 11 , evergreen broadleaf forest; 12 (red), urban and built-up land.

\subsection{LULC data}

Three LULC datasets from USGS, UMD, and MODIS have been applied to the CONUS domain at a $20 \mathrm{~km}$ resolution using a dominant class aggregation approach from the native $1 \mathrm{~km}$ resolution data. The USGS and UMD data were both derived from the AVHRR satellite measurements based on the maximum monthly normalized difference vegetation index (NDVI) composites collected from April 1992 through March 1993 (Hansen and Reed, 2000). While the USGS data were created using the 12-monthly maximum NDVI values as the inputs into an unsupervised clustering algorithm, the UMD data were based on all five AVHRR channels (ranging from 0.58 to $12.5 \mu \mathrm{m}$ ) and the NDVI that were used to derive the 41 multitemporal metrics with a supervised classification tree algorithm. The MODIS data were also derived using a supervised classification method that relied on both a global site database and the spectral information collected by MODIS. It was based on the collection four MODIS/Terra data from the period of 1 January to 31 December 2001 (http: $/ /$ duckwater.bu.edu/lc/mod12q1.html). The system for terrestrial ecosystem parameterization was developed and applied to create the global site database to serve as the training sites for MODIS land classification estimate and evaluation. Spectral information from MODIS's seven land bands and the enhanced vegetation index product were used to provide the amount and fractional cover of live vegetation within each pixel. It should be noted that this study is not intended to as- sess the LULC in a particular year but to examine the impact of different LULC on air quality. Therefore, the data based on different satellite sensors/methods and different years would provide the necessary LULC contrast for the purpose.

Table 1 shows the percentage of areas in agreement for the eight land categories that are commonly labeled for all three datasets. It can be seen that in the areas designated as evergreen needleleaf forest in MODIS, only $76.2 \%$ bear the same category in USGS and $62.3 \%$ in UMD. The discrepancies for the evergreen broadleaf forest are especially large, probably because the overall area of this category is small and the algorithms employed in three datasets are insensitive to distinguishing it in the CONUS domain. The agreement between USGS and UMD for urban and built-up land is more than $95 \%$ largely because both UMD and USGS datasets adopt this land type from the populated places' data layer in the Digital Chart of the World (Danko, 1992). Combining these eight land categories together, the overall agreements of MODIS/USGS and MODIS/UMD are $55.8 \%$ and $53.7 \%$, respectively. The overall agreement between USGS and UMD stands at $47.8 \%$.

Following the method by Hansen and Reed (2000), the land cover categories (non-water) in each of three LULC datasets were aggregated and compared with each other for the CONUS domain. In addition to the eight common LULCs listed in Table 1, four more LULCs were added. They were (1) cropland/natural land mosaic (cropland/grassland mosaic and cropland/woodland mosaic from USGS, none 
from UMD, and cropland/natural vegetation mosaic from MODIS); (2) open shrubland (mixed shrubland/grassland and savanna from USGS, open shrublands from UMD, and open shrublands and savanna from MODIS); (3) closed shrubland (shrubland from USGS, wooded grassland and closed shrublands from UMD, and closed shrublands and woody savannas from MODIS); and (4) woodland (wooded wetland and wooded tundra from USGS, woodland from $\mathrm{UMD}$, and none from MODIS). Figure 1 shows the spatial distributions of the comparison. Both UMD and MODIS replace the large portions of open shrubland designated in USGS in the Central Valley of California with croplands. In comparison to USGS and MODIS, UMD replaces the large portions of cropland and natural land mosaic with closed shrubland from northwestern to southeastern Minnesota; the large portions of cropland with closed shrubland along the border of Iowa and Missouri; the large potions of croplands, grasslands, and open shrubland with closed shrubland in eastern Kansas, central Oklahoma, and eastern Texas; and the large portions of cropland and cropland mosaic with closed shrubland in the central Florida. Compared with USGS and UMD, MODIS expands the urban and built-up land to twice as much. These LULC differences among the three datasets would cause large impacts on atmospheric processes and air quality, as will discussed in the following sections.

The LULC influences the atmospheric processes and air quality through the various parameters pre-set in NU-WRF. For example, soil moisture (SM) plays a key role in regulating the land water and energy balances, as well as in affecting the exchanges of trace gases and particles between land and atmosphere (Seneviratne et al., 2010). Its estimate in NUWRF is based on a series of LULC parameters. Conceptually, Eq. (1) governs the land surface water mass balance:

$\frac{\mathrm{dSM}}{\mathrm{d} t}=P-\mathrm{ET}-\mathrm{SR}-D$,

where $P$ is the precipitation, ET is the evapotranspiration, SR denotes for the surface runoff, and $D$ is the drainage. Equations (2) through (4) depict the land surface energy balance:

$$
\begin{aligned}
& \frac{\mathrm{d} E}{\mathrm{~d} t}=R_{\mathrm{n}}-\mathrm{LH}-\mathrm{HFX}-\mathrm{GFX} \\
& R_{\mathrm{n}}=(1-\text { albedo }) \cdot \mathrm{SW}_{\mathrm{in}}+\mathrm{LW}_{\mathrm{in}}-\mathrm{LW}_{\text {out }} \\
& \mathrm{LW}_{\text {out }}=\text { emissivity } \cdot \sigma \cdot T^{4},
\end{aligned}
$$

where $R_{\mathrm{n}}$ is the net radiation on surface as a function of surface albedo, incoming short-wave $\left(\mathrm{SW}_{\text {in }}\right)$ and longwave $\left(\mathrm{LW}_{\text {in }}\right)$ radiation, and outgoing longwave radiation $\left(\mathrm{LW}_{\text {out }}\right)$. LH is the latent heat flux, HFX is the sensible heat flux, and GFX is the ground heat flux. $\sigma$ is the Stefan-Boltzmann constant and $T$ is the land surface temperature. It is readily seen that surface water and energy balances are coupled through ET and LH, which are directly linked to SM.

Table 2 summarizes the land areas and key parameters of each LULC dataset that are employed in the Noah LSM.
Each land cover class is associated with a particular parameter value as governed by lookup tables in Noah. These parameters are crucial to the balances of land-vegetationatmosphere energy, momentum, and water. For example, land surface emissivity and albedo are important for determining L-A energy exchange (Eqs. 2 through 4), while SHDFAC, LAI, and RS are keys to estimate ET. Working together, these LSM parameters contribute to the solving of the land surface energy and water balance in the model, which subsequently are coupled to and impact upon important atmospheric processes - e.g., temperature, wind, cloud, and boundary layer structure, as well as atmospheric chemistry and air quality.

\subsection{Model evaluation}

The results of the NU-WRF simulations were compared to the available observations from both ground and space platforms. The measurements of two meteorological parameters, air temperature at $2 \mathrm{~m}(T 2)$ and water vapor content at $2 \mathrm{~m}$ $(Q 2)$, were obtained from the NCEP ADP Global Upper Air and Surface Weather Observations database (ADP: http://rda. ucar.edu/datasets/ds337.0/). The measurements of two surface air quality components, $\mathrm{O}_{3}$ and particulate matter with aerodynamic diameter less than $2.5 \mu \mathrm{m}\left(\mathrm{PM}_{2.5}\right)$, were obtained from the Air Quality System (AQS) maintained by the USEPA (http://www.epa.gov/ttn/airs/airsaqs/). The aerosol optical depth (AOD) observations at various wavelengths were obtained either from the ground based Aerosol Robotic Network (AERONET, http://aeronet.gsfc.nasa.gov/) or from the MODIS sensors on board the satellites Terra and Aqua, as well as the Multi-angle Imaging Spectroradiometer (MISR) sensor onboard Terra (http://disc.sci.gsfc.nasa.gov/giovanni/ overview/index.html). Three statistical measures were computed for the model evaluation. They are the normalized bias (NB), normalized gross error (NGE), and correlation coefficient ( $R$ value).

Table 3 lists the comparison statistics for the experiments. E_USGS is chosen as the baseline simulation due to its wide usage in the WRF modeling community. The domain average bias for $T 2$ is less than $1 \mathrm{~K}$, with the largest negative bias (approximately $2 \mathrm{~K}$ ) found in the northeastern US. The NGE for $Q 2$ ranged from $10.2 \%$ in the southeastern US to $23.1 \%$ in the Rocky Mountain areas with the domain average as about $14 \%$. While NU-WRF simulated surface $\mathrm{O}_{3}$ shows less than $20 \% \mathrm{NGE}$ and more than $0.6 R$ value when averaged over the entire domain, its performance on $\mathrm{PM}_{2.5}$ is lackluster. Figure 2 illustrates the probability distributions of surface $\mathrm{O}_{3}$ and $\mathrm{PM}_{2.5}$ statistics from each individual site. Overall, $78.6 \%$ of the $994 \mathrm{O}_{3}$ sites have NB within $\pm 15 \%$ and $99.2 \%$ have NGE less than $35 \%$, in which around $78 \%$ sites satisfy both aforementioned thresholds that were recommended by USEPA (1991) for acceptable performance of a photochemical model. On the other hand, $58.5 \%$ of the $470 \mathrm{PM}_{2.5}$ sites have NB within $\pm 30 \%$ and $50.2 \%$ 

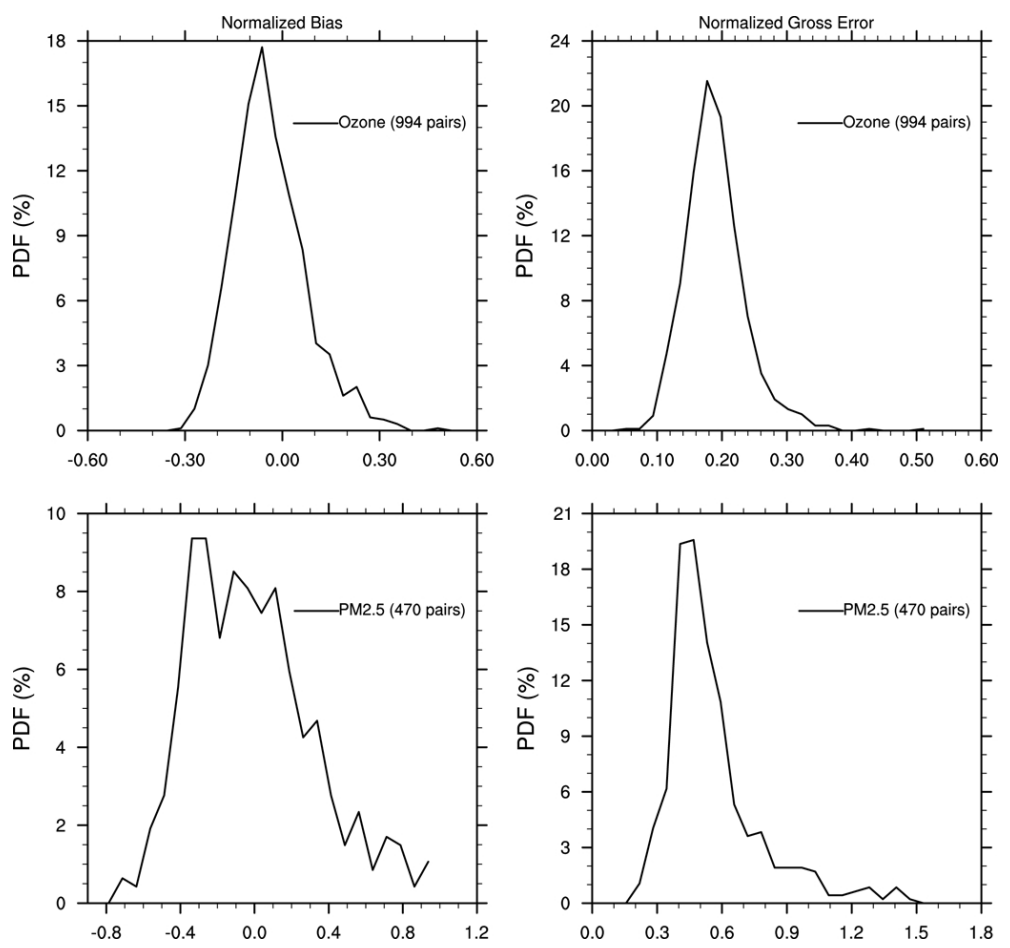

Fig. 2. Probability distributions of NB and NGE from individual site for the E_USGS.

have NGE smaller than $50 \%$. When examining the model results integrated through the entire vertical layers (column AOD), NU-WRF commonly underestimates aerosols in comparison with the AERONET and satellite measurements. It compares better to the AERONET AODs but noticeably worse to both the MODIS and MISR observations. Both the E_UMD and E_MODIS yield the similar statistics for the model/observation comparison when averaged over the entire CONUS domain (Table 3). If only urban grids are selected for comparison, however, the E_MODIS gives the least biases for both ozone (2.4\% NB vs. more than $5 \%$ from the E_USGS and E_UMD) and $\mathrm{PM}_{2.5}$ (7.7\% NB vs. $26.1 \%$ for the E_USGS and $16.9 \%$ for the E_UMD).

\section{Results and discussion}

In order to quantify the impacts of LULC data on the complex interactions of the coupled L-A system, the results are broken down according to the "process chain" of Santanello et al. (2011). This enables the causal effects of different land cover types and associated parameters to be distinguished as the effects are felt into the atmosphere and chemistry components of the model.

\subsection{Soil moisture (SM) and soil temperature (ST)}

Figure 3 (top panels) shows the spatial distributions of 5day average SM and ST over the CONUS domain from the
E_USGS. In general, the soil is wet in eastern US and dry in the southwest region (left top panel). Over $0.3 \mathrm{~m}^{3} \mathrm{~m}^{-3}$ values are common in the Midwest and the Great Plains, where the dominant LULC is cropland or cropland/natural land mosaic. High SM is also found along the North Pacific coast areas and northern Montana. On the other hand, low SM (less than $0.06 \mathrm{~m}^{3} \mathrm{~m}^{-3}$ ) is seen in southeastern California and the central boarder areas of Arizona and Utah, whose LULC is barren land or shrubland. The average SM spatial pattern follows closely to that of the initial SM from the $3.5 \mathrm{yr}$ spin-up simulation of the offline LIS, implying a long soil memory that warrants an extended LIS spin-up to allow reaching equilibrium.

In comparison with the E_USGS, E_UMD yields 30-50\% wetter soil in large portions of eastern Texas and central Florida (left middle panel) because the woodland and closed shrubland designated in UMD have larger RS (Table 2) than that of the designated cropland in USGS, which results in less ET and thus retains water better. In addition, E_UMD produces approximately $15 \mathrm{~mm}$ more precipitation (figure not shown) over the central Florida for the simulation period that may also contribute to the wetter soil there. Urban LULC features large RS and low LAI (Table 2) and urban expansion found in MODIS leads to small ET that explains the $8 \%$ more soil water than that based on USGS whose land cover is designated as cropland (left bottom panel). Urban LULC also bears low albedo and emissivity (Table 2), which, based on Eqs. (3) and (4), allows more energy to be absorbed by land. It subsequently leads to an approximately 
Table 2. Land cover classification and its associated key parameter values.

\begin{tabular}{|c|c|c|c|c|c|c|c|}
\hline Land Category & Area $\left(\mathrm{km}^{2}\right)$ & Emissivity & SHDFAC & $Z 0(\mathrm{~m})$ & LAI & $\mathrm{RS}\left(\mathrm{s} \mathrm{m}^{-1}\right)$ & Albedo \\
\hline \multicolumn{8}{|l|}{ USGS (24) } \\
\hline Urban and Built-up Land & 43600 & 0.880 & 0.10 & 0.50 & 1.00 & 200.0 & 0.15 \\
\hline Dryland Cropland and Pasture & 1303200 & $0.92-0.985$ & 0.80 & $0.05-0.15$ & $1.56-5.68$ & 40.0 & $0.17-0.23$ \\
\hline Irrigated Cropland and Pasture & 80400 & $0.93-0.985$ & 0.80 & $0.02-0.10$ & $1.56-5.68$ & 40.0 & $0.20-0.25$ \\
\hline Mixed Cropland and Pasture & 0 & $0.92-0.985$ & 0.80 & $0.05-0.15$ & $1.00-4.50$ & 40.0 & $0.18-0.23$ \\
\hline Cropland/Grassland Mosaic & 977200 & $0.92-0.980$ & 0.80 & $0.05-0.14$ & $2.29-4.29$ & 40.0 & $0.18-0.23$ \\
\hline Cropland/Woodland Mosaic & 469200 & $0.93-0.985$ & 0.80 & 0.20 & $2.00-4.00$ & 70.0 & $0.16-0.20$ \\
\hline Grassland & 1495200 & $0.92-0.960$ & 0.80 & $0.10-0.12$ & $0.52-2.90$ & 40.0 & $0.19-0.23$ \\
\hline Shrubland & 2000800 & 0.930 & 0.70 & $0.01-0.05$ & $0.50-3.66$ & 300.0 & $0.25-0.30$ \\
\hline Mixed Shrubland/Grassland & 26800 & $0.93-0.950$ & 0.70 & $0.01-0.06$ & $0.60-2.60$ & 170.0 & $0.22-0.30$ \\
\hline Savanna & 237600 & 0.920 & 0.50 & 0.15 & $0.50-3.66$ & 70.0 & 0.20 \\
\hline Deciduous Broadleaf Forest & 951200 & 0.930 & 0.80 & 0.50 & $1.85-3.31$ & 100.0 & $0.16-0.17$ \\
\hline Deciduous Needleleaf Forest & 0 & $0.93-0.940$ & 0.70 & 0.50 & $1.00-5.16$ & 150.0 & $0.14-0.15$ \\
\hline Evergreen Broadleaf Forest & 26000 & 0.950 & 0.95 & 0.50 & $3.08-6.48$ & 150.0 & 0.12 \\
\hline Evergreen Needleleaf Forest & 1673200 & 0.950 & 0.70 & 0.50 & $5.00-6.40$ & 125.0 & 0.12 \\
\hline Mixed Forest & 1054400 & $0.93-0.970$ & 0.80 & $0.20-0.50$ & $2.80-5.50$ & 125.0 & $0.17-0.25$ \\
\hline Water Bodies & 5542800 & 0.980 & 0.00 & 0.0001 & 0.01 & 100.0 & 0.08 \\
\hline Herbaceous Wetland & 0 & 0.950 & 0.60 & 0.20 & $1.50-5.65$ & 40.0 & 0.14 \\
\hline Wooded Wetland & 11200 & 0.950 & 0.60 & 0.40 & $2.00-5.80$ & 100.0 & 0.14 \\
\hline Barren or Sparsely Vegetated & 78400 & 0.900 & 0.01 & 0.01 & $0.10-0.75$ & 999.0 & 0.38 \\
\hline Herbaceous Tundra & 0 & 0.920 & 0.60 & 0.10 & $0.41-3.35$ & 150.0 & $0.15-0.20$ \\
\hline Wooded Tundra & 2800 & 0.930 & 0.60 & 0.30 & $0.41-3.35$ & 150.0 & $0.15-0.20$ \\
\hline Mixed Tundra & 0 & 0.920 & 0.60 & 0.15 & $0.41-3.35$ & 150.0 & $0.15-0.20$ \\
\hline Bare Ground Tundra & 0 & 0.900 & 0.30 & $0.05-0.10$ & $0.41-3.35$ & 200.0 & 0.25 \\
\hline Snow or Ice & 0 & 0.950 & 0.00 & 0.001 & 0.01 & 999.0 & $0.55-0.70$ \\
\hline \multicolumn{8}{|l|}{ UMD (13) } \\
\hline Evergreen Needleleaf Forest & 1105200 & 0.950 & 0.70 & 0.50 & $5.00-6.40$ & 125.0 & 0.12 \\
\hline Evergreen Broadleaf Forest & 15200 & 0.950 & 0.95 & 0.50 & $3.08-6.48$ & 150.0 & 0.12 \\
\hline Deciduous Needleleaf Forest & 0 & $0.93-0.940$ & 0.70 & 0.50 & $1.00-5.16$ & 150.0 & $0.14-0.15$ \\
\hline Deciduous Broadleaf Forest & 683600 & 0.930 & 0.80 & 0.50 & $1.85-3.31$ & 100.0 & $0.16-0.17$ \\
\hline Mixed Forests & 725200 & $0.93-0.970$ & 0.80 & $0.20-0.50$ & $2.80-5.50$ & 125.0 & $0.17-0.25$ \\
\hline Woodlands & 1358800 & 0.950 & 0.70 & 0.50 & $5.00-6.40$ & 125.0 & 0.12 \\
\hline Wooded Grassland & 1382400 & 0.930 & 0.70 & $0.01-0.05$ & $0.50-3.66$ & 300.0 & $0.25-0.30$ \\
\hline Closed Shrublands & 495600 & 0.930 & 0.70 & $0.01-0.05$ & $0.50-3.66$ & 300.0 & $0.25-0.30$ \\
\hline Open Shrublands & 1160800 & $0.93-0.950$ & 0.70 & $0.01-0.06$ & $0.60-2.60$ & 170.0 & $0.22-0.30$ \\
\hline Grasslands & 1596800 & $0.92-0.960$ & 0.80 & $0.10-0.12$ & $0.52-2.90$ & 40.0 & $0.19-0.23$ \\
\hline Croplands & 1678800 & $0.92-0.985$ & 0.80 & $0.05-0.15$ & $1.56-5.68$ & 40.0 & $0.17-0.23$ \\
\hline Bare Ground & 130000 & 0.900 & 0.01 & 0.01 & $0.10-0.75$ & 999.0 & 0.38 \\
\hline Urban & 55600 & 0.880 & 0.10 & 0.50 & 1.00 & 200.0 & 0.15 \\
\hline \multicolumn{8}{|l|}{ MODIS (20) } \\
\hline Evergreen Needleleaf Forest & 1114400 & 0.950 & 0.70 & 0.50 & $5.00-6.40$ & 125.0 & 0.12 \\
\hline Evergreen Broadleaf Forest & 120800 & 0.950 & 0.95 & 0.50 & $3.08-6.48$ & 150.0 & 0.12 \\
\hline Deciduous Needleleaf Forest & 0 & $0.93-0.940$ & 0.70 & 0.50 & $1.00-5.16$ & 150.0 & $0.14-0.15$ \\
\hline Deciduous Broadleaf Forest & 752800 & 0.930 & 0.80 & 0.50 & $1.85-3.31$ & 100.0 & $0.16-0.17$ \\
\hline Mixed Forests & 1327200 & $0.93-0.970$ & 0.80 & $0.20-0.50$ & $2.80-5.50$ & 125.0 & $0.17-0.25$ \\
\hline Closed Shrublands & 29200 & 0.930 & 0.70 & $0.01-0.05$ & $0.50-3.66$ & 300.0 & $0.25-0.30$ \\
\hline Open Shrublands & 1741600 & $0.93-0.950$ & 0.70 & $0.01-0.06$ & $0.60-2.60$ & 170.0 & $0.22-0.30$ \\
\hline Woody Savannas & 107200 & 0.930 & 0.70 & $0.01-0.05$ & $0.50-3.66$ & 300.0 & $0.25-0.30$ \\
\hline Savannas & 11600 & 0.920 & 0.50 & 0.15 & $0.50-3.66$ & 70.0 & 0.20 \\
\hline Grasslands & 2375600 & $0.92-0.960$ & 0.80 & $0.10-0.12$ & $0.52-2.90$ & 40.0 & $0.19-0.23$ \\
\hline Permanent Wetlands & 4000 & 0.950 & 0.60 & 0.30 & $1.75-5.72$ & 70.0 & 0.14 \\
\hline Croplands & 1691600 & $0.92-0.985$ & 0.80 & $0.05-0.15$ & $1.56-5.68$ & 40.0 & $0.17-0.23$ \\
\hline
\end{tabular}


Table 2. Continued.

\begin{tabular}{|c|c|c|c|c|c|c|c|}
\hline Land Category & Area $\left(\mathrm{km}^{2}\right)$ & Emissivity & SHDFAC & $Z 0(\mathrm{~m})$ & LAI & $\operatorname{RS}\left(\mathrm{s} \mathrm{m}^{-1}\right)$ & Albedo \\
\hline \multicolumn{8}{|l|}{ MODIS (20) } \\
\hline Urban and Built-up & 115600 & 0.880 & 0.10 & 0.50 & 1.00 & 200.0 & 0.15 \\
\hline Cropland/Natural Vegetation Mosaic & 912000 & $0.92-0.980$ & 0.80 & $0.05-0.14$ & $2.29-4.29$ & 40.0 & $0.18-0.23$ \\
\hline Snow and Ice & 0 & 0.950 & 0.00 & 0.001 & 0.01 & 999.0 & $0.55-0.70$ \\
\hline Barren or Sparsely Vegetated & 102000 & 0.900 & 0.01 & 0.01 & $0.10-0.75$ & 999.0 & 0.38 \\
\hline Water & 5568400 & 0.980 & 0.00 & 0.0001 & 0.01 & 100.0 & 0.08 \\
\hline Wooded Tundra & 0 & 0.930 & 0.60 & 0.30 & $0.41-3.35$ & 150.0 & $0.15-0.20$ \\
\hline Mixed Tundra & 0 & 0.920 & 0.60 & 0.15 & $0.41-3.35$ & 150.0 & $0.15-0.20$ \\
\hline Barren Tundra & 0 & 0.900 & 0.30 & $0.05-0.10$ & $0.41-3.35$ & 200.0 & 0.25 \\
\hline
\end{tabular}

Table 3. Summary of statistics comparing with observations.

\begin{tabular}{|c|c|c|c|c|c|c|c|c|c|c|}
\hline \multirow{3}{*}{$\begin{array}{l}\text { Data Source } \\
\text { \# of pairs }\end{array}$} & $T 2$ & $Q 2$ & $\mathrm{O}_{3}$ & $\mathrm{PM}_{2.5}$ & $550 \mathrm{~nm}$ & $555 \mathrm{~nm}$ & $380 \mathrm{~nm}$ & $500 \mathrm{~nm}$ & $675 \mathrm{~nm}$ & $870 \mathrm{~nm}$ \\
\hline & ADP & ADP & AQS & AQS & MODIS & MISR & \multicolumn{4}{|c|}{ AOD from AERONET } \\
\hline & 177022 & 153350 & 73267 & 52895 & 3718 & 2897 & 110 & 112 & 115 & 132 \\
\hline \multicolumn{11}{|l|}{ E_USGS } \\
\hline NB (\%) & -0.37 & 0.10 & -5.10 & 3.77 & -26.6 & -55.4 & -29.4 & -24.9 & -11.7 & -16.4 \\
\hline $\operatorname{NGE}(\%)$ & 0.89 & 14.1 & 18.8 & 57.1 & 86.3 & 59.8 & 43.2 & 40.1 & 40.5 & 41.7 \\
\hline$R$ value & 0.86 & 0.87 & 0.62 & 0.35 & 0.20 & 0.23 & 0.46 & 0.53 & 0.49 & 0.43 \\
\hline \multicolumn{11}{|l|}{ E_MODIS } \\
\hline $\mathrm{NB}(\%)$ & -0.33 & 0.05 & -4.51 & 2.68 & -26.6 & -55.6 & -30.2 & -25.5 & -12.4 & -16.9 \\
\hline $\operatorname{NGE}(\%)$ & 0.88 & 14.3 & 18.8 & 56.9 & 86.3 & 59.8 & 42.6 & 39.4 & 39.9 & 41.4 \\
\hline$R$ value & 0.86 & 0.86 & 0.61 & 0.35 & 0.20 & 0.24 & 0.48 & 0.55 & 0.50 & 0.43 \\
\hline \multicolumn{11}{|l|}{ E_UMD } \\
\hline $\mathrm{NB}(\%)$ & -0.25 & 0.00 & -3.89 & 2.98 & -26.6 & -55.5 & -30.9 & -26.0 & -13.1 & -17.4 \\
\hline $\operatorname{NGE}(\%)$ & 0.88 & 14.0 & 18.7 & 57.1 & 86.0 & 59.8 & 43.0 & 40.1 & 40.4 & 41.7 \\
\hline$R$ value & 0.86 & 0.86 & 0.62 & 0.34 & 0.20 & 0.23 & 0.47 & 0.53 & 0.49 & 0.42 \\
\hline
\end{tabular}

$\mathrm{NB}=\frac{\text { sim-obs }}{\mathrm{obs}} \times 100 \% ; \mathrm{NGE}=\frac{\mid \text { sim-obs } \mid}{\mathrm{obs}} \times 100 \% ; R$ value $=$ correlation coefficient.

$3 \mathrm{~K}$ higher soil temperature (right bottom panel) found in urban LULC of E_MODIS than that found in the same locations of E_USGS where the LULC is cropland. The differences of albedo and emissivity in various LULC also explain the changes in ST found between the E_UMD and E_USGS (right middle panel).

Averaged over the land of the CONUS domain, the average SM and ST are $0.2289 \mathrm{~m}^{3} \mathrm{~m}^{-3}$ and $291.22 \mathrm{~K}$, respectively, from the E_USGS. After receiving $1.98 \%$ (i.e., $0.25 \mathrm{~mm}_{\text {grid }^{-1}}$, or approximately $2.61 \mathrm{~km}^{3}$ water over the domain's land) more precipitation, E_UMD's SM is $1.92 \%$ more than that based on the E_USGS. Although it produces $0.38 \%$ (i.e., $0.05 \mathrm{~mm}_{\text {grid }^{-1}}$ ) more precipitation, the E_MODIS gives an almost same average SM as that from the E_USGS. Compared with the average ST from the E_USGS, E_UMD models approximately $0.22 \mathrm{~K}$ higher ST, while E_MODIS estimates around $0.02 \mathrm{~K}$ lower ST.

\subsection{Latent heat flux (LH) and sensible heat flux (HFX)}

The most direct impact of SM in the LSM is on the calculation of ET, as reflected in upward moisture flux (QFX) and LH. As expected, QFX (figure not shown) and LH bear the very similar spatial distribution patterns as illustrated in Fig. 4, left panels. High QFX results in high LH. Typically, higher LH is found over the wetter soil. High (up to $200 \mathrm{~W} \mathrm{~m}^{-2}$, left top panel) $\mathrm{LH}$ is seen over the large portions of the Great Plains where SM is generally more than $0.3 \mathrm{~m}^{3} \mathrm{~m}^{-3}$, while low (less than $25 \mathrm{~W} \mathrm{~m}^{-2}$ ) $\mathrm{LH}$ is common over the areas of southern Nevada, southeastern California, and southwestern Arizona, where SM is typically smaller than $0.1 \mathrm{~m}^{3} \mathrm{~m}^{-3}$. It is worth noting that there is comparable SM along the North Pacific coast areas of Washington and Oregon to that of the Great Plains, but its LH ranges between 25 and $100 \mathrm{~W} \mathrm{~m}^{-2}$, only $1 / 4$ to $1 / 2$ of its counterparts in the Great Plains. This is because the cropland/grassland 

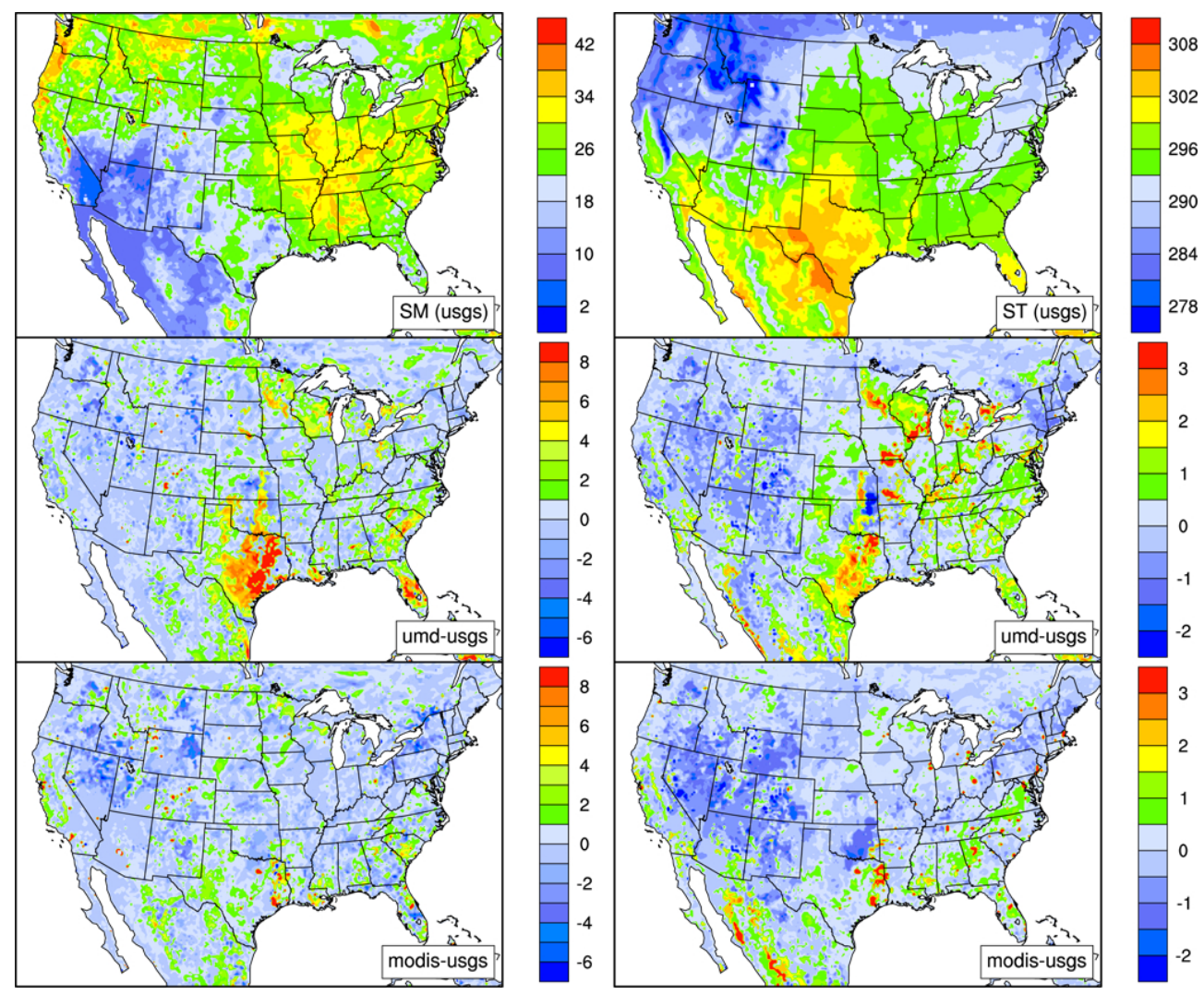

Fig. 3. Spatial distribution of top soil moisture (SM, \%, left panels) and average top soil temperature (ST, K, right panels) simulated using the USGS LULC and their differences with the results using the UMD (umd-usgs) and MODIS (modis-usgs) LULC.

designated in the Great Plains have much smaller RS than the evergreen needleleaf forest in the North Pacific coast areas (40 vs. $125 \mathrm{~s} \mathrm{~m}^{-1}$, Table 2), which leads to the higher ET and the subsequent higher LH in the Great Plains. Contrary to LH, high HFX is typically seen over the dry soil (Fig. 4, right panels). The high HFX found in the dry soil agrees with the study by Bindlish et al. (2001), who used the microwave remote sensing data to model the linkage between SM and HFX. The dry southwestern US typically sees an HFX more than $130 \mathrm{~W} \mathrm{~m}^{-2}$, while the wet eastern US experiences a less than $40 \mathrm{~W} \mathrm{~m}^{-2}$ of HFX. The major metropolitan areas generally experience higher HFX than the surrounding areas following the land-air temperature gradient, exactly the opposite spatial pattern of that of LH. Taking the E_USGS as an example and defining the surrounding areas as one grid extension of each direction of an urban grid, the average urban LULC sees an approximately $93 \%$ higher HFX but $68 \%$ lower LH.

Compared to the E_USGS, the E_UMD generates 15 to $25 \mathrm{~W} \mathrm{~m}^{-2}$ lower LH in the Central Valley areas of California, the corridor areas extending from eastern Kansas, central Oklahoma, to northern Texas, and the sporadic areas in the eastern US. On the other hand, the E_UMD generates up to $35 \mathrm{~W} \mathrm{~m}^{-2}$ more LH in the limited area of northeast- ern Texas and the sporadic areas of the eastern US. This can all be traced back to the different LULC assignments in USGS and UMD, as well as the resulting precipitation contrast found in the E_USGS and E_UMD. For example, USGS designates the LULC in the aforementioned corridor areas as grassland/mixed forest $\left(\mathrm{RS}=125 \mathrm{~s} \mathrm{~m}^{-1}\right.$ ) but UMD denotes it as closed shrubland $\left(\mathrm{RS}=300 \mathrm{~s} \mathrm{~m}^{-1}\right)$. Obviously with the similar precipitation, closed shrubland tends to retain water better and then causes the lower QFX and LH. Meanwhile, although the limited areas of northeastern Texas is designated as cropland and evergreen needleleaf forest in USGS as opposed to closed shrubland in UMD, it receives at least $20 \mathrm{~mm}$ more rainfall, which leads to the higher QFX and LH found in the E_UMD. Again, the large urban $\left(\mathrm{RS}=200 \mathrm{~s} \mathrm{~m}^{-1}\right)$ expansion shown in MODIS explains the lower QFX an LH simulated over the major metropolitan areas in comparison to that from the E_USGS. The domain-wide average QFX and $\mathrm{LH}$ for land are approximately $107 \mathrm{~g} \mathrm{~m}^{-2} \mathrm{~h}$ and $74 \mathrm{~W} \mathrm{~m}^{-2}$, respectively, from the E_USGS. The discrepancies among the results from the E_USGS, E_UMD, and E_MODIS are all within $0.3 \%$.

In comparison with the E_USGS, the E_UMD (Fig. 4, right middle panel) produces approximately $1.3 \%$ higher HFX over the land, with the largest increases (up to $35 \mathrm{~W} \mathrm{~m}^{-2}$ ) 

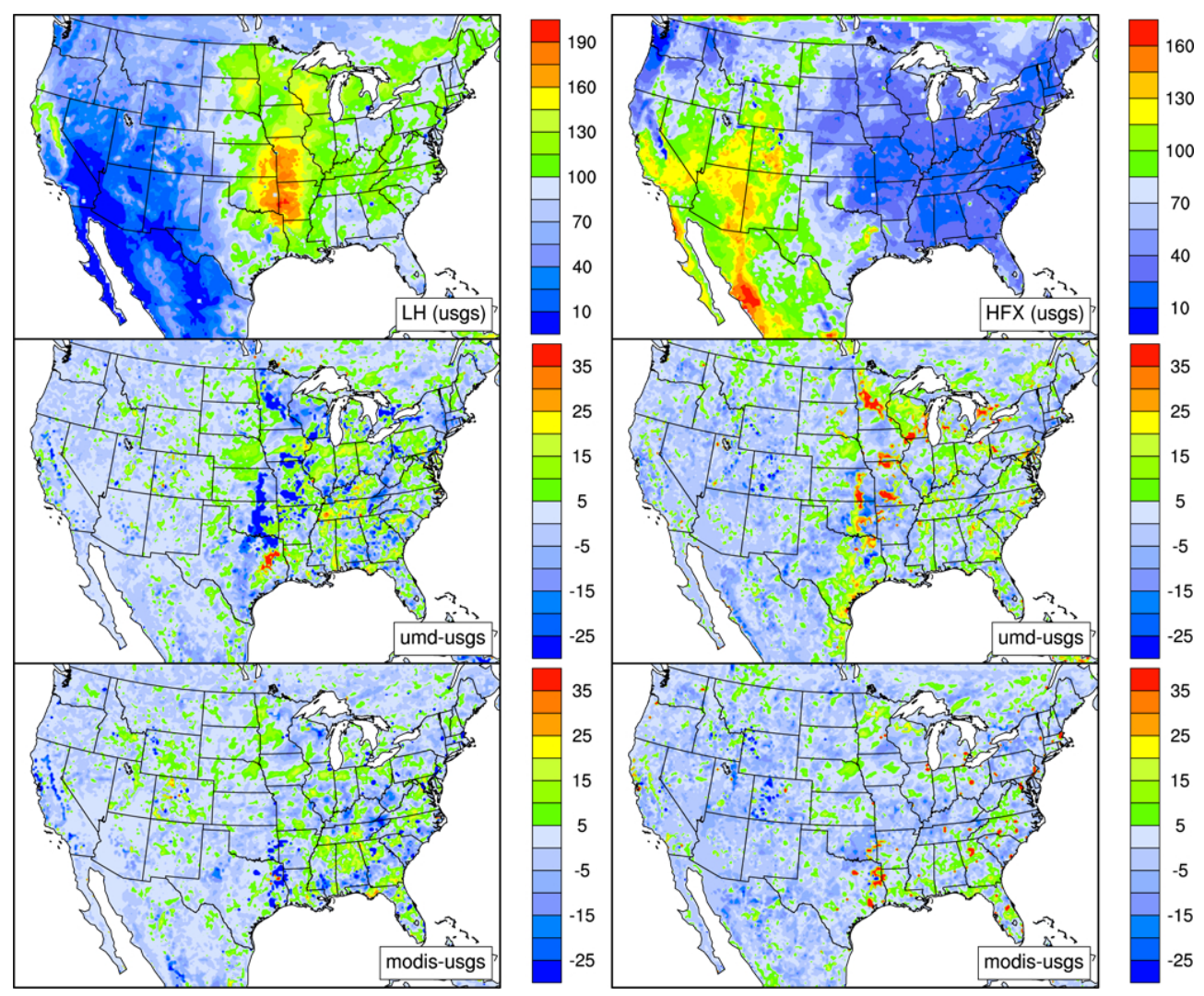

Fig. 4. Same as Fig. 3 except for average latent heat flux ( $\mathrm{LH}, \mathrm{W} \mathrm{m}^{-2}$, left panels) and sensible heat flux (HFX, $\mathrm{W} \mathrm{m}^{-2}$, right panels).

occurring in the scattering regions in the Midwest and the Great Plains. The detailed LULC investigation reveals that the LULC changes with the large RS contrast give the big differences in temperature gradient and HFX. The areas with the largest HFX increases are usually designated as the closed shrubland in UMD while as the cropland or grassland in USGS. The largest HFX decreases occur where the LULC is forest or shrubland mixture in USGS and grassland or cropland in UMD. On average, the E_MODIS (Fig. 4, right bottom panel) generates around $1 \%$ lower HFX over the land than the E_USGS. However, the expanded urban areas found in MODIS do see a higher HFX and temperature gradient. The observation that large RS contrast results in big HFX change holds for this instance as well.

\subsection{Air temperature at $2 \mathrm{~m}(\mathrm{~T} 2)$ and water vapor content at $2 \mathrm{~m}\left(Q^{2}\right)$}

The land surface energy and water budgets reflected in QFX, LH, and HFX would impact the near-surface air temperature and moisture as illustrated in Fig. 5. The left panels display the spatial distributions of $Q 2$. Similar to SM, the eastern US generally finds a high $Q 2$ (more than $0.01 \mathrm{~kg} \mathrm{~kg}^{-1}$ ) and the southwestern US sees less than $0.004 \mathrm{~kg} \mathrm{~kg}^{-1} Q 2$. However, the northwestern US, where the high SM comparable with the eastern US is modeled, sees about half of $Q 2$ as that of the eastern US, which follows that of QFX, reflecting that some LULCs retain soil water better than the others. In comparison to the E_USGS, the E_UMD simulates lower $Q 2$ in the large portions of the Midwest and the Great Plains but higher $Q 2$ in the sporadic areas of the eastern US. The spatial pattern of the lower $Q 2$ appears to correspond to the lower LH (Fig. 4, left middle panel) but the spatial distribution of the higher $Q 2$ seems more of the effect of boundary layer structure shallow PBLH implies less entrainment of dry and warm air into the PBL from the free atmosphere, thus a higher $Q 2$. The urban and built-up land tends to have lower $Q 2$, as can be seen in Fig. 5, left bottom panel. In the region where it is designated as urban and built-up land in MODIS but not in USGS, $Q 2$ is around $3 \%$ higher from the E_USGS than from the E_MODIS.

The spatial distribution of $T 2$ (Fig. 5, right panels) follows the ST distribution closely with high temperature (up to 303 $\mathrm{K}$ ) found in Texas and low (approaching the freezing point) found along the Rocky Mountains. This is anticipated since the heat conduction by the land contributes significantly to warm up the near-surface air. The $T 2$ difference maps (i.e., E_UMD vs. E_USGS, and E_MODIS vs. E_USGS) mimic those of the ST as well but with a smaller contrast - typically $0.5 \sim 1 \mathrm{~K}$ lower than the corresponding ST differences. As expected, the spatial distribution of ST- $T 2$ gradient mimics 

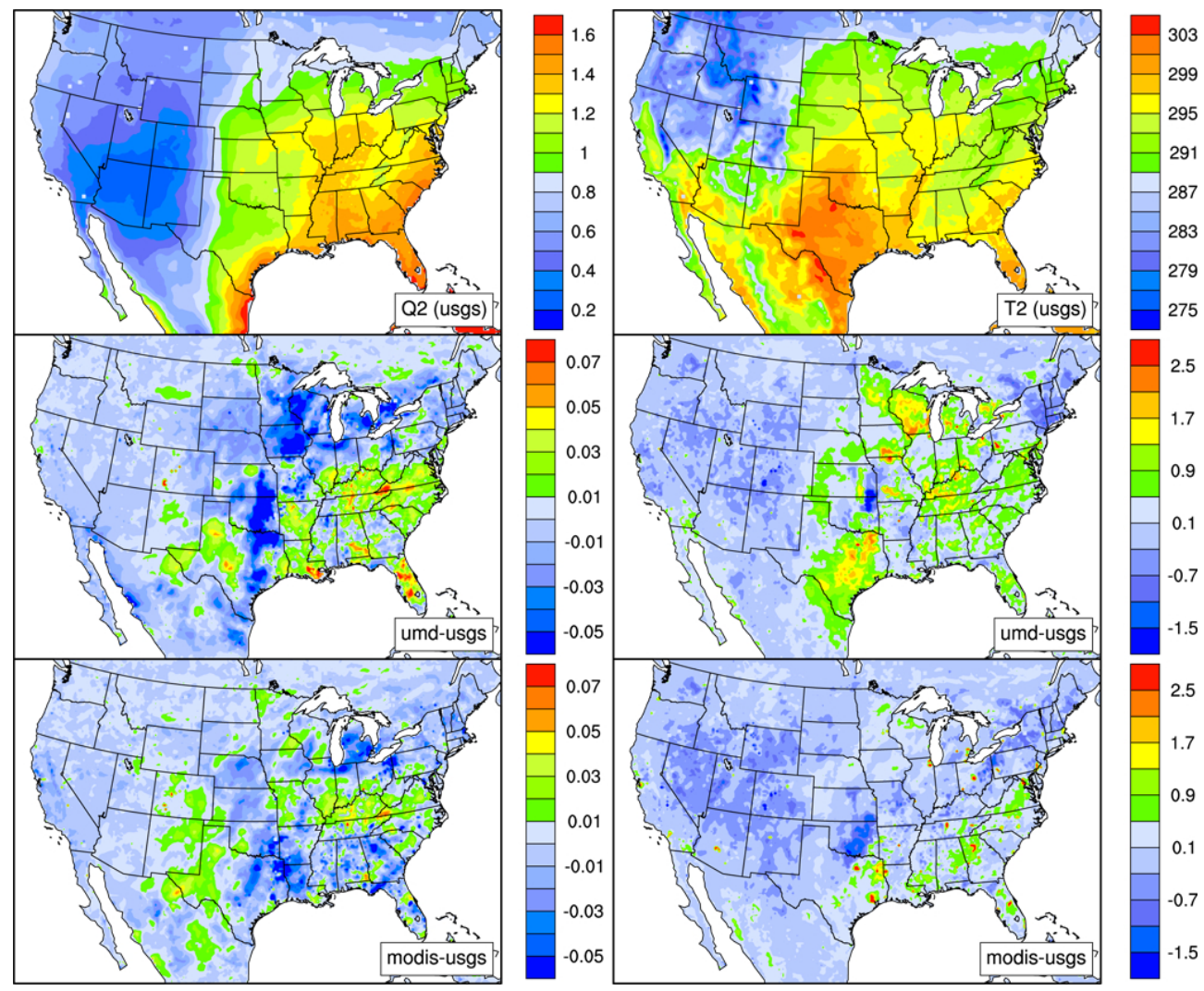

Fig. 5. Same as Fig. 3 except for average water vapor content $(Q 2, \%$, left panels) and air temperature (T2, K, right panels) at $2 \mathrm{~m}$.

the one of HFX since $T 2$ is determined with HFX and surface skin temperature (e.g., Miglietta et al., 2009). The wet eastern US has a small temperature gradient (less than $0.2 \mathrm{~K}$ for the vast areas), while the dry southwestern region experiences a high (typically more than $4 \mathrm{~K}$ ) temperature gradient. Following the case of HFX, the average urban LULC sees an approximately $1 \mathrm{~K}$ warmer $T 2$ than the surrounding areas. The LULC-difference-induced temperature change would influence biogenic emissions and thermal chemical reaction processes that consequently would alter the atmospheric composition and air quality.

\subsection{Wind speed and planetary boundary layer height (PBLH)}

The LH, HFX, and QFX calculated from the land surface model provide the lower boundary conditions for the vertical transport simulation, and thus impact the PBL structure and its evolution, as reflected in PBLH. Figure 6 (left panels) displays the average PBLH spatial distribution from the E_USGS (left top panel) and its comparisons with the results from the E_UMD (left middle panel) and E_MODIS (left bottom panel). It can be found that the PBLH distribution appears similar to the HFX distribution. This agrees with the physical basis for PBL growth being primarily driven by the buoyancy fueled by surface heating, and was confirmed by observations obtained from the AMMA campaign (Kohler et al., 2010). The high PBLH is found in the dry southwestern US, with the maximum (more than $1700 \mathrm{~m}$ ) being in western Texas and central New Mexico and the minimum (less than $400 \mathrm{~m}$ ) in eastern Mississippi and central Alabama. The daytime PBLH map closely mimics the daily average map with the maximum PBLH exceeding $4000 \mathrm{~m}$ in western Texas. During nighttime, however, the highest PBLH (up to $700 \mathrm{~m}$ ) is found in the Great Plains. It is worth noting that during daytime the average PBLH over the urban areas (approximately $1400 \mathrm{~m}$ ) is about $14 \%$ higher than that of the surrounding areas, while at night the average PBLH over the urban areas is about $10 \mathrm{~m}$ smaller than that over the surrounding areas. The daily average urban PBLH (around $620 \mathrm{~m}$ ) is approximately $11 \%$ more than the PBLH of the surrounding areas.

The PBLH contrast maps (Fig. 6, left middle and bottom panels) appear to follow those of HFX as well. The replacement of the low/high RS LULC in USGS with the high/low RS LULC in UMD tends to enhance/suppress the PBLH found in the E_UMD. The enhanced PBLH (around $116 \mathrm{~m}$ larger than that from the E_USGS) found in the urban LULC from the E_MODIS is explained by the large expansion of urban coverage in MODIS that reduces the ET. The PBLH change caused by the LULC change would impact 

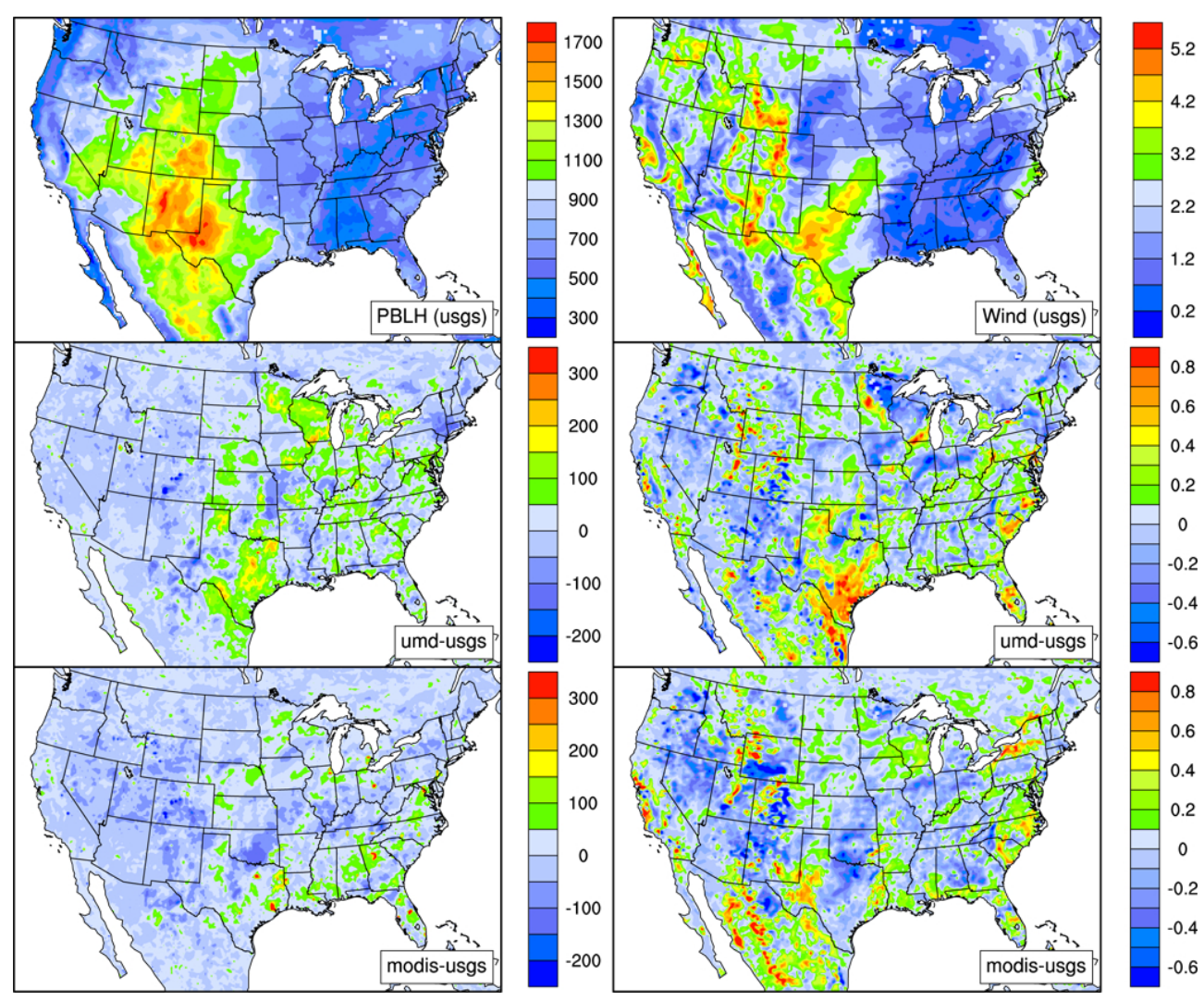

Fig. 6. Same as Fig. 3 except for average PBL height (PBLH, $\mathrm{m}$, left panels) and surface wind speed ( $\mathrm{m} \mathrm{s}^{-1}$, right panels).

the vertical mixing of heat, moisture, momentum, and mass, and have a profound effect on air quality. In addition, deeper PBLH growth implies larger entrainment of dry and warm air into the PBL from the free atmosphere. This feedback then favors a warmer, drier PBL as reflected in the resultant $T 2$ and $Q 2$ conditions with implications for atmospheric chemistry.

Figure 6 (right panels) illustrates the surface wind speed that is directly affected by the LULC through friction and, to a lesser extent, through the LULC impacts on heat fluxes as demonstrated in the previous sections. As compared to the E_USGS, the E_UMD and E_MODIS generate slightly higher average surface wind $\left(1.98 \mathrm{~m} \mathrm{~s}^{-1}\right.$ and $1.99 \mathrm{~m} \mathrm{~s}^{-1}$ vs. $1.97 \mathrm{~m} \mathrm{~s}^{-1}$, respectively) for the land with the largest changes (approximately $1 \mathrm{~m} \mathrm{~s}^{-1}$ ) occurring in southern Texas, the central Florida, and the scattered areas across the rest of the US (right middle panel), as well as the noticeable decrease (up to $0.6 \mathrm{~m} \mathrm{~s}^{-1}$ ) in south Wyoming and the scattered areas of the other parts of the US (right bottom panel). The LULC examination reveals that, in general, the wind speed increases when the LULC with large Z0 in USGS is replaced with the LULC with small $Z 0$ in the other datasets, and vice verse. For example, the LULC in southern Texas is designated as cropland or cropland/natural land mosaic $(Z 0=0.05-0.20 \mathrm{~m})$ in USGS. When it is replaced with the closed shrubland $(Z 0=0.01-0.05 \mathrm{~m})$ in UMD, the average wind speed increases by $0.6-1.0 \mathrm{~m} \mathrm{~s}^{-1}$. On the other hand, when the LULC in south Wyoming designated as the shrubland or shrubland mixture in USGS is replaced with the grassland $(Z 0=0.10-0.12 \mathrm{~m})$ in MODIS, the average wind speed decreases by $0.6 \mathrm{~m} \mathrm{~s}^{-1}$. The changed surface wind impacts soil erosion and dust emissions, as well as affects the horizontal movements of mass and energy, which subsequently impact air quality, as will be discussed in the following sections.

\subsection{Emissions of dust and biogenic volatile organic compound (BVOC)}

The dust emissions in this study are estimated using the GOCART dust model (Ginoux et al., 2001). The emissions only occur in the region where the erodibility map designates it as a dust source. Soil texture and moisture, together with the surface wind speed, determine the total dust emissions. The drier the soil and the stronger the wind, the more dust emitted over the areas where its erodibility is more than zero. Figure 7 (left top panel) displays the average dust emissions from the E_USGS and its differences with the results from the E_UMD (left middle panel) and the E_MODIS (left bottom panel). Large dust emissions (up to $30 \mathrm{~kg} \mathrm{~km}^{-2} \mathrm{~h}$ ) are obtained over the Mojave Desert located primarily in 

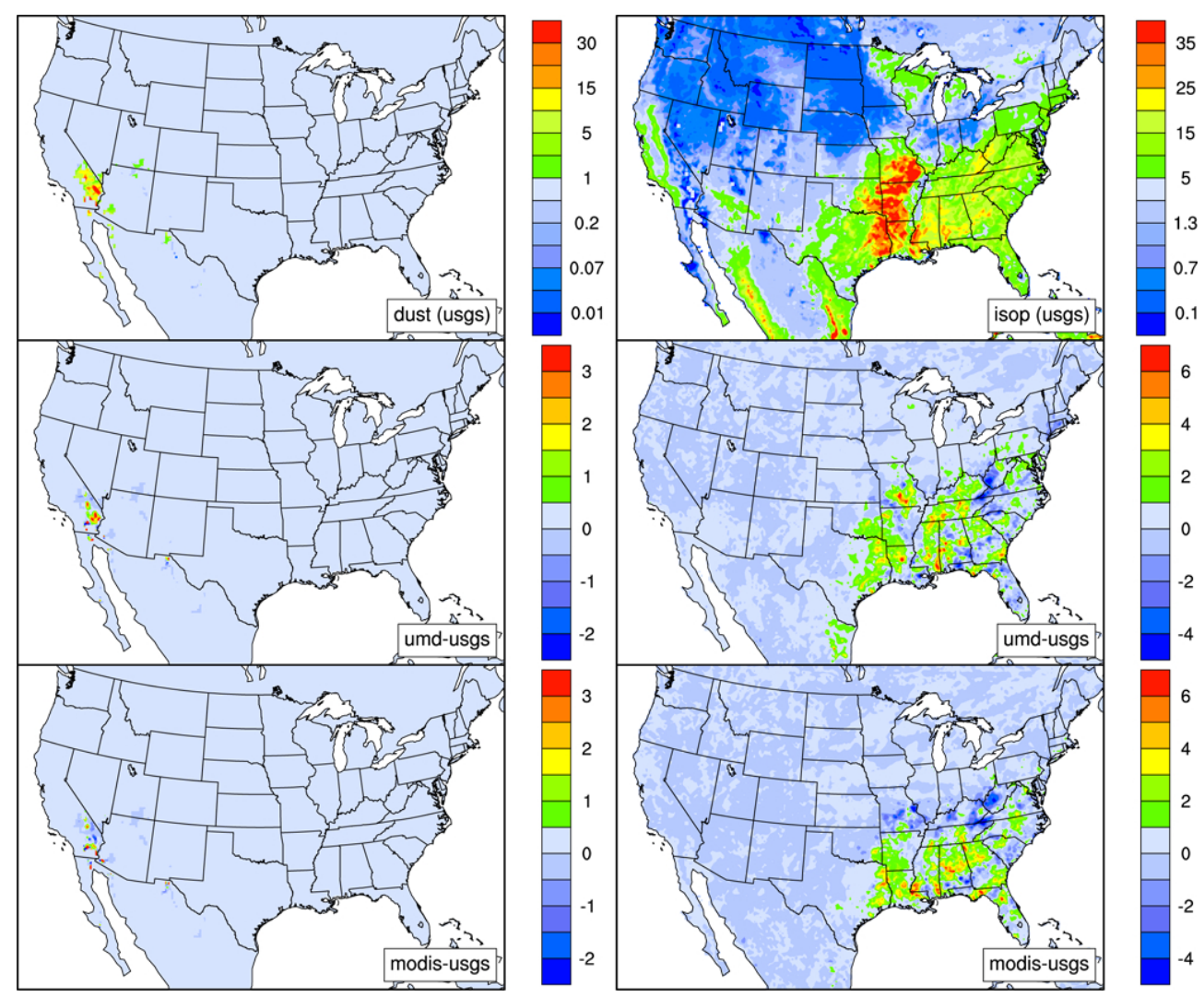

Fig. 7. Same as Fig. 3 except for average dust emissions ( $\mathrm{kg} \mathrm{km}^{-2} \mathrm{~h}$, left panels) and biogenic isoprene emissions ( $\mathrm{mol} \mathrm{km}^{-2} \mathrm{~h}$, right panels).

southeastern California. The noticeable dust emissions are also found over the Sonoran Desert located in southern California, southwestern Arizona, and northwestern Mexico, as well as over the Chihuahuan Desert in southern Arizona and New Mexico, southwestern Texas, and northern Mexico. The average daily dust emissions over the CONUS are 37735, 39221, and 39105 metric tons from the E_USGS, E_UMD, and E_MODIS, respectively, which are comparable with the April average dust load (40 500 metric tons day $^{-1}$ ) over North America estimated by Park et al. (2010) using their newly developed windblown dust module. The SM role in the change in dust emissions due to the LULC data selection is negligible and the increase/decrease in emissions is almost all attributed to the wind speed difference induced by the different LULC data usage.

Biogenic emissions depend on the LULC and the surrounding environment (Guenther et al., 2006). In this study, the LULC data used in the biogenic emissions module, MEGAN2, are based on both AVHRR and MODIS that are different from either LULC used in the experiments. Therefore, the discussion on the impact of the LULC data on BVOC emissions is limited to the indirect effects through the emissions adjustment by the ambient temperature and solar radiation that would be altered by the LULC change, as discussed in the previous sections. Figure 7 (right panels) illus- trates the spatial distribution of the average biogenic isoprene emissions from the E_USGS and its contrast maps in comparison with the E_UMD and E_MODIS. Large isoprene emissions are observed in the eastern US with the peak (more than $35 \mathrm{~mol} \mathrm{~km}^{-2} \mathrm{~h}$ ) occurring in the Ozarks (covering southern Missouri and northern Arkansas) and eastern Texas/western Louisiana. This spatial distribution matches the results by $\mathrm{Xu}$ et al. (2002), who employed the AVHRR data and the Biogenic Emission Inventory System (BEIS) model to estimate the isoprene emissions for the eastern US, and by Tao et al. (2003), who also employed BEIS. The isoprene emissions contrast maps (right middle and bottom panels) closely follow the spatial distributions of the surface temperature contrasts (Fig. 5, right panels). The difference can reach more than $6 \mathrm{~mol} \mathrm{~km} \mathrm{~km}^{-2} \mathrm{~h}$. Over the CONUS domain, the daily average isoprene emissions are approximately 88752 metric tons based on the E_USGS. The results from the E_UMD and E_MODIS are $3.1 \%$ and $1.5 \%$ higher than that of the E_USGS, respectively, and are largely a function of higher $T 2$ from the E_UMD and E_MODIS. As an ozone precursor, isoprene emissions changes are therefore reflected in air quality difference. 

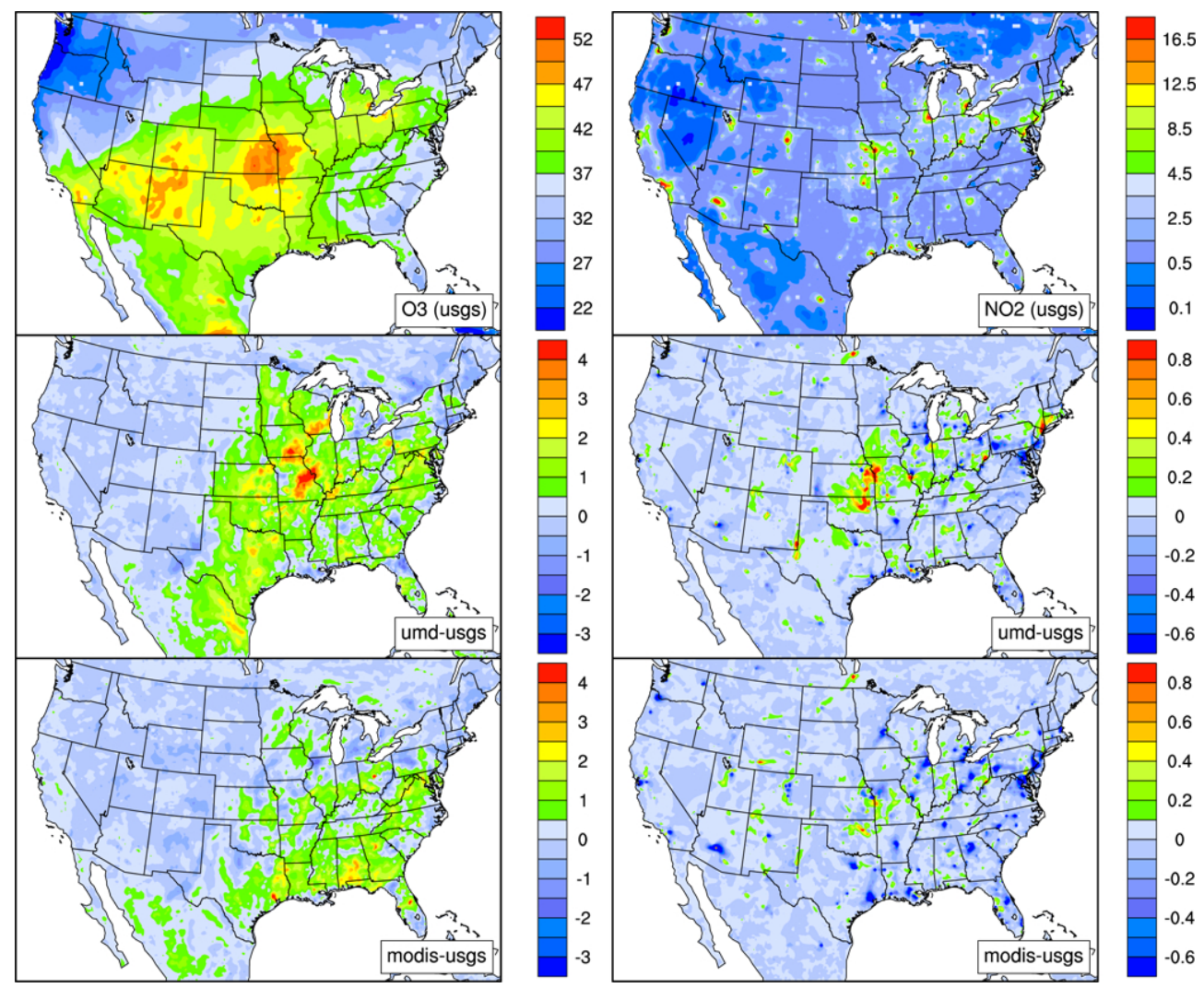

Fig. 8. Same as Fig. 3 except for average surface ozone concentration (ppbv, left panels) and $\mathrm{NO}_{2}$ concentration (ppbv, right panels).

\subsection{Air quality}

The LULC change induces changes in meteorological fields, e.g., the temperature, wind, and PBLH, as well as in emissions, which results in a profound impact on air quality. High temperature generally favors ozone formation. Strong wind moves the pollutants fast and further away. Deep PBL is good for pollutant vertical mixing. Emissions directly enter the atmospheric pollutants mass balance. Three pollutants - ozone, nitrogen dioxide $\left(\mathrm{NO}_{2}\right)$, and $\mathrm{PM}_{2.5}$ - are used as proxy to discuss the LULC impact on air quality. Ozone is a criterion pollutant regulated by the USEPA. As a secondary pollutant (i.e., not directly emitted from a source), ozone forms in the presence of its precursors under the favorable meteorological conditions, e.g., stagnant high-pressure system featuring strong solar radiation and high air temperature (e.g., Seinfeld and Pandis, 2006). $\mathrm{NO}_{2}$, on the other hand, is a primary pollutant that is emitted from a large pool of anthropogenic and natural sources. It is also regulated by the USEPA and is one of the two (the other is VOC) key precursors of ozone.

Figure 8 displays the spatial distributions of average surface ozone concentration (left panels) and $\mathrm{NO}_{2}$ (right panels) from the E_USGS and their contrast maps to the results from the E_UMD and E_MODIS. As a primary pollutant, $\mathrm{NO}_{2}$ distributes heterogeneously in space with high concentrations centering in the major metropolitan regions and the
Ohio River Valley, where large emissions sources are identified. The urban grids observe, on average, more than twofold of surface $\mathrm{NO}_{2}$ than the surrounding areas (14.2 ppbv vs. $6.7 \mathrm{ppbv})$. On the other hand, the secondary ozone experiences a relatively homogenously spatial distribution. Relatively high ozone (more than $45 \mathrm{ppbv}$ ) is seen in the southern Great Plains and southern California. The difference between urban and the surrounding areas is small with the urban grids observing less than 2 ppbv of surface ozone than the surrounding grids.

In comparison with the E_USGS, both the E_UMD and E_MODIS produce higher $\mathrm{NO}_{2}$ along the Missouri/Kansas border and northeastern Oklahoma, and generate remarkably lower $\mathrm{NO}_{2}$ in the major metropolitan regions. The reasons are multifold. First, in northeastern Oklahoma and the border areas of Missouri/Kansas, the E_UMD and E_MODIS observe a shallower PBLH (Fig. 6, left panels), which, due to the more limited volume for vertical mixing, leads to higher $\mathrm{NO}_{2}$ concentrations. Second, the lower temperature found in the above regions slows down the thermal decomposition of peroxyacyl nitrates (PAN, Atkinson et al., 2006), an important atmospheric reservoir species of $\mathrm{NO}_{2}$, thus keeping $\mathrm{NO}_{2}$ in the air longer and supporting its buildup. Last but not the least, the oxidized formation of $\mathrm{HNO}_{3}$ from $\mathrm{NO}_{2}$ by hydroxyl radicals and the subsequent dry/wet $\mathrm{HNO}_{3}$ 
deposition represent the major $\mathrm{NO}_{2}$ removal mechanism in the atmosphere (e.g., Seinfeld and Pandis, 2006). The dry deposition velocity of $\mathrm{HNO}_{3}$ (figure not shown) is lower in those regions reducing the $\mathrm{NO}_{2}$ removal from the atmosphere. The aforementioned reasons also explain what happens in the metropolitan areas. In the regions where all three datasets designate the LULC as urban and built-up land, the E_UMD and E_MODIS observe the respective $0.25 \mathrm{ppbv}$ and 0.78 ppbv lower $\mathrm{NO}_{2}$ concentrations averaged over the urban grids as compared to the results from the E_USGS. The averaged $\mathrm{HNO}_{3}$ dry deposition velocity and surface temperature from the E_UMD and E_MODIS are approximately $0.2 \mathrm{~cm} \mathrm{~s}^{-1}$ larger and $0.5 \mathrm{~K}$ higher, respectively, than from the E_USGS favoring the reduced $\mathrm{NO}_{2}$. The largely enhanced PBLH from the E_UMD (around $35 \mathrm{~m}$ deeper) and E_MODIS further dilutes $\mathrm{NO}_{2}$ as compared to that from the E_USGS.

In the rural areas where ozone formation is almost always limited to the availability of $\mathrm{NO}_{\mathrm{x}}$ (i.e., $\mathrm{NO}_{2}+\mathrm{NO}$ ), meteorology can largely explain the difference among each experiment. For example, up to 4 ppbv more ozone is observed in the stretched areas of the Midwest from the E_UMD than from the E_USGS (Fig. 8, left middle panel). Higher $T 2$ simulated in those areas is one of the key drivers for this observation - higher temperature not only increases soil NO emissions (e.g., Williams et al., 1992; Tao et al., 2003) that fuel ozone formation there but also favors the thermodynamics of ozone generation. The replacement of cropland designated in USGS with forest/closed shrubland in UMD results in the reduced ozone dry deposition velocity for the aforementioned areas, thus the increased ozone concentration. The smaller ozone dry deposition velocity found in forest than in cropland is consistent with the results from a model study by Miao et al. (2006). The deeper PBLH from the E_UMD in those areas (Fig. 6, left panels) reduces surface ozone concentration but not enough to totally offset the ozone increase due to the changes in temperature and dry deposition. Moreover, as discussed in Sect. 3.4, deeper PBLH tends to entrain more warm and dry air from the free troposphere that may favor ozone generation. The net PBLH effect on ozone air quality therefore highly depends on the competition of vertical mixing and photochemical formation. In the urban areas, however, where either $\mathrm{NO}_{\mathrm{x}}$ or VOC can limit ozone formation, the explanation is not that straightforward. As discussed in the $\mathrm{NO}_{2}$ comparison, the PBLH and surface temperature from the E_MODIS are both higher than from the E_USGS. The effects of these two factors on ozone formation are potentially opposite. In addition, in the $\mathrm{NO}_{\mathrm{x}}$-limited regime the deep PBLH-induced surface $\mathrm{NO}_{\mathrm{x}}$ decrease would further suppress ozone formation, while in the VOC-limited regime the reduced $\mathrm{NO}_{\mathrm{x}}$ tends to produce more ozone due to the reduced $\mathrm{NO}_{\mathrm{x}}$ titration effect (e.g., Seinfeld and Pandis, 2006). Together these effects cause a moderate average ozone differences (within $0.5 \mathrm{ppbv}$ ) over the urban grids among the three experiments.
From the air quality regulation perspective, it is also interesting to know how the LULC impacts the frequency of high ozone occurrences. It is found that there are 467 occurrences of surface $8 \mathrm{~h}$-average ozone concentration exceeding 75 ppbv, the National Ambient Air Quality Standard for ozone set by the USEPA (http://www.epa.gov/air/criteria. $\mathrm{html}$ ), from the E_USGS. The E_UMD and E_MODIS generate $32 \%$ and $3 \%$ more high ozone occurrences, respectively.

$\mathrm{PM}_{2.5}$ is another criterion pollutant and can be both primary and secondary origin. The spatial distributions (figures not shown) of average surface $\mathrm{PM}_{2.5}$ from the E_USGS and its difference with the E_UMD and E_MODIS are similar to those of $\mathrm{NO}_{2}$ (Fig. 8, right panels), with more than $10 \mu \mathrm{g} \mathrm{m}^{-3}$ being common in major metropolitan areas and the Midwest. The main difference between spatial distributions of $\mathrm{NO}_{2}$ and $\mathrm{PM}_{2.5}$ is that very high concentrations (greater than $35 \mu \mathrm{g} \mathrm{m}^{-3}$ ) are found in southern California, southwestern Arizona, and northwestern Mexico, where the wind-blown dust emissions dominate. The smaller PBLH and less rainfall (thus less wet removal) found in the Missouri/Kansas border and northeastern Oklahoma from the E_UMD as compared to that from the E_USGS largely explains the higher $\mathrm{PM}_{2.5}$ (up to $4 \mu \mathrm{g} \mathrm{m}^{-3}$ ) in those regions based on the E_UMD. Similarly, the larger PBLH in the urban areas simulated from the E_MODIS contributes the reduced $\mathrm{PM}_{2.5}$ there.

\subsection{Implication of urbanization effect on ozone air quality}

According to the 2010 US census, approximately $80.7 \%$ of the population lives in urban areas (http://www.census.gov/ geo/www/ua/2010urbanruralclass.html). The highly populated urban areas present a distinct local climate featuring some unique phenomenon such as urban heat islands as a result of complex interactions between humans and nature e.g., changes in short/long-wave solar radiation due to large emissions (albedo and emissivity), changes in airflow due to increased friction ( $Z 0)$, and reduced ET due to vegetation removal (RS) (e.g., Coutts et al., 2007). The subsequent impacts on air quality and human health can be large and need to be investigated.

The two LULC datasets used in this study, USGS and MODIS, present a large difference in urban LULC coverage, with MODIS designating over twofold as much urban area as USGS doing. Although the large increase in urban coverage in MODIS is not solely caused by physical urban expansions over the periods 1992-1993 and 2001 (land class definition in the LULC datasets also plays an important role), it does provide an opportunity to study what would be expected if urban expansions continue to occur. It should be noted that the emissions inventory employed in the experiments are the same; therefore, the air quality change discussed below is solely caused by the LULC-induced meteorological change. This change can be as a result of gradients between urban and the surrounding land and/or local effects. Over the areas 
Table 4. Comparison of key parameters associated with urban ozone air quality over the MODIS urban areas.

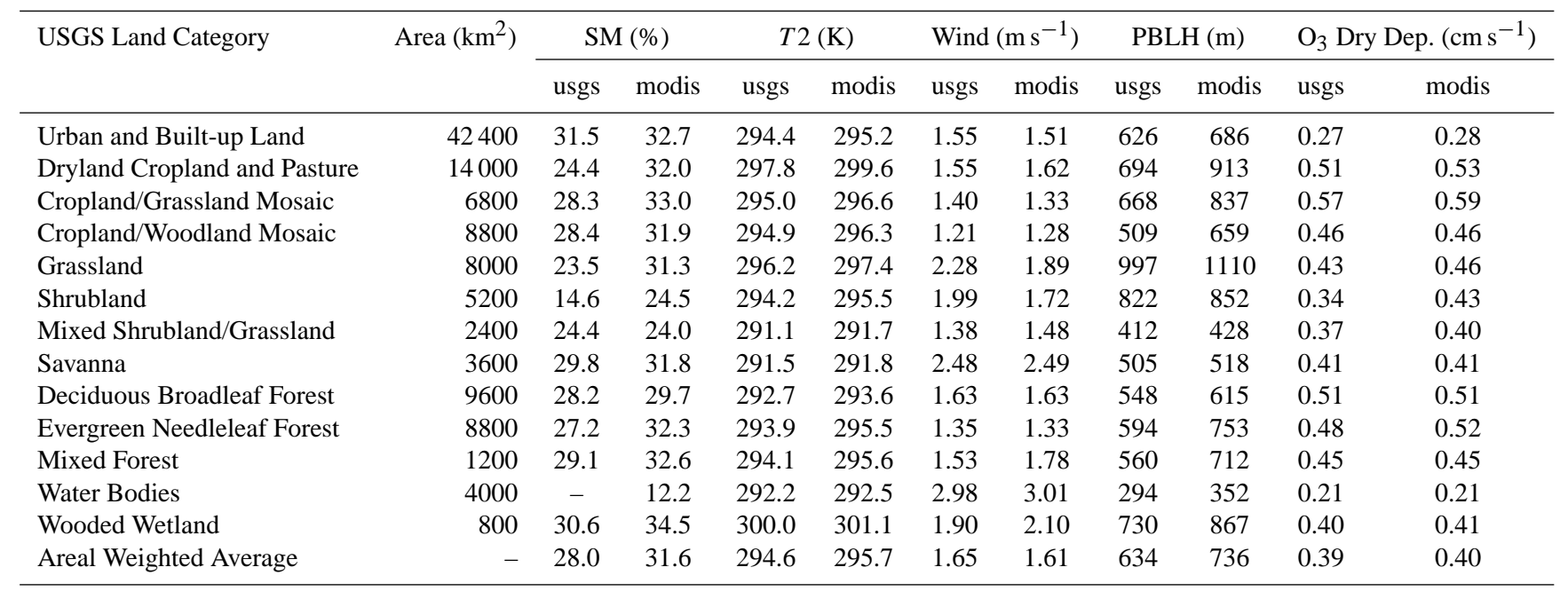

designated as urban by both MODIS and USGS, the gradients are the major driving force of the modeled differences since the land characteristics are the same for the same land categories from the different LULC datasets (see Table 2). Over the areas designated as urban by MODIS but defined as non-urban by USGS, however, both local effects (through different land characteristics, e.g., roughness, albedo, LAI, and RS) and gradients play roles in modeled discrepancies between the E_USGS and E_MODIS.

Table 4 summarizes the averages of some parameters key to ozone air pollution. It can be found that only $36.7 \%$ of the MODIS urban is designated as urban and built-up land in USGS, with various croplands $(25.6 \%)$, various forests $(17.0 \%)$, grassland $(6.9 \%)$, and shrubland $(4.5 \%)$ rounding up to the top five LULC in USGS for the MODIS urban. As a result, the SM increases by $13 \%$ over the MODIS urban areas as compared to the same regions from the E_USGS with the large SM change (greater than $30 \%$ ) occurring where shrubland, dryland cropland/pasture, or grassland is converted into urban area. On average, $T 2$ increases by $1.1 \mathrm{~K}$ based on the E_MODIS, with the large increases observed where urban area sprawls into cropland or forest. PBLH experiences the increase across all the USGS LULCs that are designated as urban by MODIS, with the largest enhancement $(219 \mathrm{~m})$ happening in the places that used to be dryland cropland/pasture. Surface wind speed changes in both directions. While converting grassland and shrubland into urban tends to decrease it, urban sprawling into mixed forest or wooded wetland is likely to increase wind speed. On average, surface wind speed displays a small decrease (less than $3 \%$ ) during the urbanization. Ozone dry deposition velocity undergoes a moderate change (less than $5 \%$ ) as well with the largest increase (approximately $26 \%$ ) occurring in the places where shrubland in USGS changes to urban in MODIS.

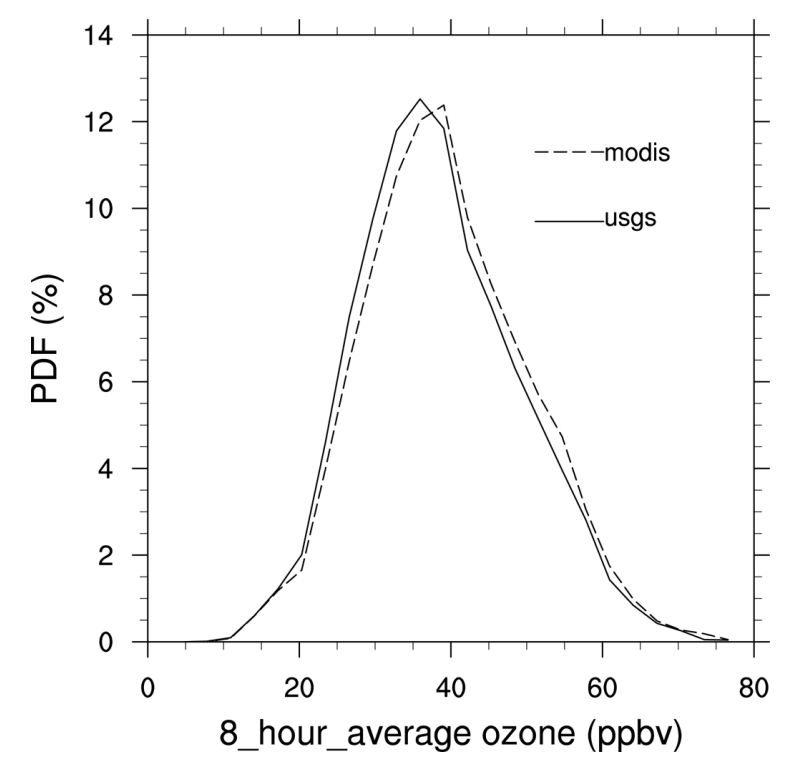

Fig. 9. Probability distributions of surface 8 h-average ozone for the E_USGS and E_MODIS.

The net effect of the aforementioned factors on surface ozone is to increase its mean $8 \mathrm{~h}$-average concentration by $1 \mathrm{ppb}$ when converting the non-urban grids in USGS into urban coverage in MODIS, with the large changes occurring where croplands (1.7 ppb increase) or forests (1.4 ppb increase) are cleared for urban settings. Figure 9 illustrates the probability distributions of surface $8 \mathrm{~h}$-average ozone over the non-urban grids in USGS but the urban grids in MODIS. It can be seen that urbanization generally tends to produce more ozone (MODIS vs. USGS). It reduces the occurrence of low ozone (i.e., less than $30 \mathrm{ppbv}$ ) by approximately $12 \%$ and increases the high ozone frequency (i.e., more than $70 \mathrm{ppbv}$ ) by over $50 \%$. However, the average peak ozone 
(i.e., more than $75 \mathrm{ppbv}$ ) appears reduced from $79 \mathrm{ppbv}$ in the E_USGS to $77 \mathrm{ppbv}$ in the E_MODIS. It should be noted that the anthropogenic emissions change due to urbanization has not been taken into account in this study. Depending on the urban emissions characteristics (e.g., $\mathrm{NO}_{\mathrm{x}}$ sensitive or VOC sensitive), such change can complicate the urban ozone issues.

\section{Summary and conclusion}

Three commonly used LULC datasets - i.e., USGS, UMD, and MODIS - have been applied to the newly developed NUWRF system to investigate the land cover effects on atmospheric processes and air quality over the CONUS domain. These three datasets display large differences in land cover classifications and assignments, where the overall agreements of MODIS/USGS, MODIS/UMD, and USGS/UMD are $55.8 \%, 53.7 \%$, and $47.8 \%$, respectively, when the eight common land classifications employed in all three datasets are considered. There are two major model procedures for this study. The three LULC datasets are first plugged in the offline LIS system for spin-up to achieve the soil equilibrium state, and the results from the offline LIS then provide the surface boundary and initial conditions to the NU-WRF. The NU-WRF results are compared with the available observations and the results show NU-WRF does a reasonably good simulation of physical, chemical, and biological processes.

The offline LIS results show that large initial SM difference (30-50\%) exists in the regions where woodland/closed shrubland changes to cropland or cropland is cleared for urban areas. The initial SM difference carries over into the NUWRF simulation to be reflected in the similar spatial pattern of the average SM distribution. It also results in a noticeable precipitation change - in comparison to the E_USGS, the E_UMD and E_MODIS produce $0.25 \mathrm{~mm}_{\text {grid }}{ }^{-1}$ and $0.05 \mathrm{~mm} \mathrm{grid}^{-1}$ more rainfall averaged over the domain land. LH and HFX distributions are closely coupled to the SM as well. Wet soil generally leads to high LH and low HFX, while dry soil does the opposite. When land with small RS changes to the one with large RS (e.g., cropland/grassland to shrubland/urban area), LH tends to decrease and HFX appears to increase. This is because RS is one key to estimate ET that is important to both water and energy cycles between the land and the atmosphere. Large RS restricts ET and allows more energy into HFX. The energy change due to land cover change at the land surface would propagate into the overlaying atmosphere and lead to changes in temperature, PBLH, and wind that are important to the atmospheric composition evolution and air quality. For example, regions with high HFX tend to have high surface temperature and deep PBLH. Therefore, change in LULC from the one favoring large ET to the one with small ET would increase surface temperature and enhance PBLH. This is what happens when cropland is converted into urban land, where the average $T 2$ increases by approximately $1 \mathrm{~K}$ and the PBLH is around $11 \%$ larger. Land with large $Z 0$ tends to have reduced surface wind, as evidenced by the $0.6-1.0 \mathrm{~m} \mathrm{~s}^{-1}$ decreases in the average wind speed in southern Texas where the shrubland in UMD is converted into the cropland in USGS.

The LULC-change-induced meteorology change would subsequently affect land surface emissions and air quality. SM and surface wind directly determine how much dust is produced and enters into the atmosphere. This study shows that it is mainly wind that dictates the dust emission changes due to the selections of different LULC datasets. Domain-wide, the E_UMD and E_MODIS respectively produce $3.9 \%$ and $3.6 \%$ more dust than the E_UDSG. Biogenic emissions are affected as well. As compared to the E_USGS, the E_UMD and E_MODIS respectively generate $3.1 \%$ and $1.5 \%$ more isoprene, and $2.7 \%$ and $0.8 \%$ more terpenes. Air quality responds to the meteorology and emissions changes in a complex way. The surface concentration of the primary pollutant $\mathrm{NO}_{2}$ tends to decrease where the deep PBL develops, such as the case of converting USGS's cropland/grassland into MODIS's urban area. The enhanced dry deposition of $\mathrm{HNO}_{3}$, a major $\mathrm{NO}_{2}$ terminal species, over urban areas also contributes to the $\mathrm{NO}_{2}$ reduction under the cropland-changed-to-urban scenario. The response of surface ozone, a secondary pollutant, to the LULC change is more complex. Although high temperature and weak wind mostly favor ozone formation, depending on the local emissions characteristics, surface ozone can be enhanced or suppressed in response to PBLH change, as evidenced under the same cropland-changed-to-urban scenario. For the simulation period, the E_UMD models noticeably more high ozone that exceeds the US surface ozone standard and the E_MODIS yields a relatively smaller increase in ozone standard violations as compared to the E_USGS.

The impact of urbanization on air quality is investigated in the context of the conceptual land cover change found in USGS and MODIS. MODIS carries greater than $100 \%$ more urban coverage than USGS. The virtual urban expansion in MODIS produces higher SM, lower LH, higher HFX, higher surface temperature, weaker wind, and deeper PBLH. As a result, surface $\mathrm{NO}_{2}$ tends to reduce, whereas surface ozone can change in both directions due to the compensating feedbacks. Overall, urbanization appears to cause less low ozone (smaller than $30 \mathrm{ppbv}$ ) but more high ozone (greater than $70 \mathrm{ppbv}$ ) occurrences.

There are several caveats in the study. First, the LULC information from different datasets has not been directly coupled into the biogenic emission and dust emission models. The LULC mismatch between the LSM and emission models brings in uncertainty in emission estimation and the subsequent air quality evaluation. As shown in Chen et al. (2009) and Wu et al. (2012), the LULC-change-induced biogenic emissions change could be large. In the future endeavor, making the LULC consistent in the different components of a modeling system would be extremely valuable. However, as 
intended, this study is able to isolate the impact of secondary (via meteorology) effects of land and atmosphere feedbacks on emissions and chemistry. Second, although it provides some insights into the consequences of LULC changes on atmospheric processes and air quality, this study employs three datasets derived from the different satellite sensors and classification methods that make the land definition inconsistent across the datasets. In the future, application of time series LULC data derived from the same sensor and same classification method will greatly improve the understanding of the impacts of LULC change on air quality, especially over the populated urban areas. The forthcoming MODIS 2010 data that will be ready for NU-WRF application (vs. MODIS 2002 as used in this study) will provide a good opportunity to do such investigation. Last but not the least, the model internal variability, which arises from the nonlinear nature of atmospheric processes such that the model is sensitive to perturbations of initial conditions (ICs) (e.g., Giorgi and $\mathrm{Bi}$, 2000; Vanvyve et al., 2008), is not explored in this study. Changes in atmospheric parameters due to physical modifications of a model are only significant when outside of the model internal variability. Based on the study by Vanvyve et al. (2008), who investigated the regional model internal variability by randomly altering the ICs, the maximum variability for 5-day-average air temperature at $10 \mathrm{~m}$ and boundary layer wind speed ranged from 0.03 to $0.18 \mathrm{~K}$, and from 0.06 to $0.31 \mathrm{~m} \mathrm{~s}^{-1}$, respectively, depending on the location in their West African domain. Giorgi and Bi (2000) conducted the model internal variability study for the eastern China domain and concluded that the model response to perturbations was insensitive to the origin, location, and the magnitude of perturbation but sensitive to the perturbation timing. The variability for the daily average surface temperature, wind speed, and water vapor content over late May to early June was within $0.1 \mathrm{~K}, 0.1 \mathrm{~m} \mathrm{~s}^{-1}$, and $0.1 \mathrm{~g} \mathrm{~kg}^{-1}$, respectively. If those numbers are assumed to be the model random error bounds, it is obvious that the modeled differences (Fig. 5 and right panel of Fig. 6) due to the usage of different LULC datasets are well beyond the model internal variability.

In conclusion, this study has shown the importance of land cover data on offline and coupled L-A and chemistry prediction. There is inconsistency amongst ancillary dataset application in the Earth system models to date, and the uncertainty introduced as a result has gone largely ignored. With continued advancements of satellite-based land cover datasets, it is therefore critical to make such assessments as were performed here.

Acknowledgements. The authors would like to thank the NASA Center for Climate Simulation (NCCS) for supercomputing and mass storage support. This research was partially funded by the NASA's Modeling, Analysis, and Prediction (MAP) program and by the NASA's Atmospheric Composition: Modeling and Analysis (ACMAP) program at the Goddard Space Flight Center of NASA.
Edited by: B. N. Duncan

\section{References}

Atkinson, R., Baulch, D. L., Cox, R. A., Crowley, J. N., Hampson, R. F., Hynes, R. G., Jenkin, M. E., Rossi, M. J., Troe, J., and IUPAC Subcommittee: Evaluated kinetic and photochemical data for atmospheric chemistry: Volume II - gas phase reactions of organic species, Atmos. Chem. Phys., 6, 3625-4055, doi:10.5194/acp-6-3625-2006, 2006.

Berge, E., Huang, H.-C., Chang, J., and Liu, T.-H.: A study of the importance of initial conditions for photochemical oxidant modeling, J. Geophys. Res., 106, 1347-1363, 2001.

Bindlish, R., Kustas, W. P., French, A. N., Diak, G. R., and Mecikalski, J. R.: Influence of near-surface soil moisture on regional scale heat fluxes: Model results using microwave remote sensing data from SGP97, IEEE T. Geosci. Remote Sens., 39, 1719-1728, 2001.

Case, J. L., Crosson, W. L., Kumar, S. V., Lapenta, W. M., and Peters-Lidard, C. D.: Impacts of High-Resolution Land Surface Initialization on Regional Sensible Weather Forecasts from the WRF model, J. Hydrometeorol., 9, 1249-1266, 2008.

Case, J. L., Kumar, S. V., Srikishen, J., and Jedlovec, G. J.: Improving Numerical Weather Predictions of Summertime Precipitation over the Southeastern United States through a High-Resolution Initialization of the Surface State, Weather Forcast., 26, 785-807, 2011.

Charusombat, U., Niyogi, D., Kumar, A., Wang, X., Chen, F., Guenther, A., Turnipseed, A., and Alapaty, K.: Evaluating a new deposition velocity module in the Noah land-surface model, Bound.Lay. Meteorol., 137, 271-290, 2010.

Chen, J., Avise J., Guenther, A., Wiedinmyer, C., Salathe, E., Jackson, R. B., and Lamb, B.: Future land use and land cover influences on regional biogenic emissions and air quality in the United States, Atmos. Envrion., 43, 5771-5780, 2009.

Cheng, F.-Y., Kim, S., and Byun, D.-W.: Application of high resolution land use and land cover data for atmospheric modeling in the Houston-Galveston Metropolitan area: Part II. Air quality simulation results, Atmos. Environ., 42, 4853-4869, 2008.

Chin, M., Ginoux, P., Kinne, S., Torres, O., Holben, B. N., Duncan, B. N., Martin, R. V., Logan, J. A., Higurashi, A., and Nakajima, T.: Tropospheric aerosol optical thickness from the GOCART model and comparisons with satellite and Sun photometer measurements, J. Atmos. Sci., 59, 461-483, 2002.

Chou, M.-D. and Suarez, M. J.: A solar radiation parameterization (CLIRAD-SW) for atmospheric studies, NASA Tech. Rep. NASA/TM-1999-10460, Washington DC, Vol. 15, 38 pp., 1999.

Coutts, A. M., Beringer, J., and Tapper, N. J.: Impact of increasing urban density on local climate: Spatial and temporal variations in the surface energy balance in Melbourne, Australia, J. Appl. Meteorol. Clim., 46, 477-493, 2007.

Danko, D. M.: The Digital Chart of the World, GeoInfo Systems, 2, 29-36, 1992.

Deardorff, J. W.: Efficient prediction of ground surface temperature and moisture with inclusion of a layer of vegetation, J. Geophys. Res., 83, 1889-1903, doi:10.1029/JC083iC04p01889, 1978.

Ek, M. B., Mitchell, K. E., Lin, Y., Rogers, E., Grunmann, P., Koren, V., Gayno, G., and Tarpley, J. D.: Implementation of Noah land surface model advances in the National Centers for 
Environmental Prediction operational mesoscale Eta Model, J. Geophys. Res., 108, 8851, doi:10.1029/2002JD003296, 2003.

Emmons, L. K., Walters, S., Hess, P. G., Lamarque, J.-F., Pfister, G. G., Fillmore, D., Granier, C., Guenther, A., Kinnison, D., Laepple, T., Orlando, J., Tie, X., Tyndall, G., Wiedinmyer, C., Baughcum, S. L., and Kloster, S.: Description and evaluation of the Model for Ozone and Related chemical Tracers, version 4 (MOZART-4), Geosci. Model Dev., 3, 43-67, doi:10.5194/gmd3-43-2010, 2010.

Friedl, M. A., McIver, D. K., Hodges, J. C. F., Zhang, X. Y., Muchnoey, D., Strahler, A. H., Woodcock, C. E., Gopal, S., Schneider, A., Cooper, A., Baccini, A., Gao, F., and Schaaf, C.: Global land cover mapping from MODIS: algorithms and early results, Remote Sens. Environ., 83, 287-302, 2002.

Ganzeveld, L., Bouwman, L., Stehfest, E., van Vuuren, D. P., Eickhout, B., and Lelieveld, J.: Impacts of future land use and land cover changes on atmospheric chemistry-climate interactions, J. Geophys. Res., 115, D23301, doi:10.1029/2010JD014041, 2010.

Ginoux, P., Chin, M., Tegen, I., Prospero, J., Holben, B., Dubovik, O., and Lin, S.-J.: Sources and global distributions of dust aerosols simulated with the GOCART model, J. Geophys. Res., 106, 20255-20273, 2001.

Giorgi, F. and Bi, X.: A study of internal variability of a regional climate model, J. Geophys. Res., 105, 29503-29521, 2000.

Grell, G. A. and Devenyi, D.: A generalized approach to parameterizing convection combining ensemble and data assimilation techniques, Geophys. Res. Lett., 29, 1693, doi:10.1029/2002GL015311, 2002.

Grell, G. A., Peckham, S. E., Schmitz, R., McKeen, S. A., Frost, G., Skamarock, W. C., and Eder, B.: Fully coupled "online" chemistry within the WRF model, Atmos. Environ., 39, 6957-6975, 2005.

Gross, A. and Stockwell, W. R.: Comparison of the EMEP, RADM2 and RACM Mechanisms, J. Atmos. Chem., 44, 151-170, 2003.

Guenther, A., Karl, T., Harley, P., Wiedinmyer, C., Palmer, P. I., and Geron, C.: Estimates of global terrestrial isoprene emissions using MEGAN (Model of Emissions of Gases and Aerosols from Nature), Atmos. Chem. Phys., 6, 3181-3210, doi:10.5194/acp-63181-2006, 2006.

Hansen, M. C. and Reed, B.: A comparison of the IGBP DISCover and University of Maryland $1 \mathrm{~km}$ global land cover products, Int. J. Remote Sens., 21, 1365-1373, 2000.

Hansen, M. C., Defries, R. S., Townshend, J. R. G., and Sohlberg, R.: Global land cover classification at $1 \mathrm{~km}$ spatial resolution using a classification tree approach, Int. J. Remote Sens., 21, 13311364, 2000.

Hong, S. Y., Noh, Y., and Dudhia, J.: A new vertical diffusion package with an explicit treatment of entrainment processes, Mon. Weather Rev., 134, 2318-2341, 2006.

Jin, M. and Liang, S.: An Improved Land Surface Emissivity Parameter for Land Surface Models Using Global Remote Sensing Observations, J. Climate, 19, 2867-2881, 2006.

Kohler, M., Kalthoff, N., and Kottmeier C.: The impact of soil moisture modifications on CBL characteristics in West Africa: A casestudy from the AMMA campaign, Q. J. Roy. Meteorol. Soc., 136, 442-455, 2010.

Kumar, A., Chen, F., Niyogi, D., Alfieri, J. G., Ek, M., and Mitchell, K.: Evaluation of a Photosynthesis-Based Canopy Resistance Formulation in the Noah Land-Surface Model, Bound.-Lay. Me- teorol., 138, 263-284, 2011.

Kumar, S. V., Peters-Lidard, C. D., Tian, Y., Houser, P. R., Geiger, J. Olden, S., Lighty, L., Eastman, J. L., Doty, B., Dirmeyer P., Adams, J., Mitchell K., Wood, E. F., and Sheffield, J.: Land Information System - An Interoperable Framework for High Resolution Land Surface Modeling, Environ. Modell. Softw., 21, 14021415, 2006.

Kumar, S. V., Peters-Lidard, C. D., Eastman, J. L., and Tao, W.K.: An integrated high resolution hydrometeorological modeling testbed using LIS and WRF, Environ. Modell. Softw., 23, 169$181,2008$.

Lin, M., Holloway, T., Carmichael, G. R., and Fiore, A. M.: Quantifying pollution inflow and outflow over East Asia in spring with regional and global models, Atmos. Chem. Phys., 10, 42214239, doi:10.5194/acp-10-4221-2010, 2010.

Loveland, T. R., Reed, B. C., Brown, J. F., Ohlen, D. O., Zhu, Z., Yang, L., and Merchant, J. W.: Development of a global land cover characteristics database and IGBP DISCover from $1 \mathrm{~km}$ AVHRR data, Int. J. Remote Sens., 21, 1303-1330, 2000.

Matsui, T., Tao, W.-K., Masunaga, H., Kummerow, C. D., Olson, W. S., Teruyuki, N., Sekiguchi, M., Chou, M., Nakajima, T. Y., Li, X., Chern, J., Shi, J. J., Zeng, X., Posselt, D. J., and Suzuki, K.: Goddard Satellite Data Simulation Unit: Multi-Sensor Satellite Simulators to Support Aerosol- Cloud-Precipitation Satellite Missions, Eos Trans., 90, Fall Meet. Suppl., Abstract A21D0268, 2009.

Miao, J.-F., Chen, D., and Wyser, K.: Modeling subgrid scale dry deposition velocity of $\mathrm{O}_{3}$ over the Swedish west coast with MM5-PX model, Atmos. Environ., 40, 415-429, 2006.

Michalakes, J., Chen, S., Dudhia, J., Hart, L., Klemp, J., Middlecoff, J., and Skamarock, W.: Development of a next generation regional weather research and forecast model, in: Developments in Teracomputing: Proceedings of the Ninth ECMWF Workshop on the use of high performance computing in meteorology, 1317 November 2000, Reading, UK, edited by: Zwieflhofer, W. and Kreitz, N., World Scientific, Singapore, 269-276, 2001.

Miglietta, F., Gioli, B., Brunet, Y., Hutjes, R. W. A., Matese, A., Sarrat, C., and Zaldei, A.: Sensible and latent heat flux from radiometric surface temperatures at the regional scale: methodology and evaluation, Biogeosciences, 6, 1975-1986, doi:10.5194/bg6-1975-2009, 2009.

Miller, D. A., and White, R. A.: A conterminous United States multilayer soil characteristics data set for regional climate and hydrology modeling, Earth Interact., Vol. 2, Paper No. 2, 1998.

Mitchell, K. E., Lohmann, D., Houser, P. R., Wood, E. F., Schaake, J. C., Robock, A., Cosgrove, B. A., Sheffield, J., Duan, Q., Luo, L., Higgins, R. W., Pinker, R. T., Tarpley, J. D., Lettenmaier, D. P., Marshall, C. H., Entin, J. K., Pan, M., Shi, W., Koren, V., Meng, J., Ramsay, B. H., and Bailey, A. A: The multi-institution North American Land Data Assimilation System (NLDAS): Utilizing multiple GCIP products and partners in a continental distributed hydrological modeling system, J. Geophys. Res., 109, D07S90, doi:10.1029/2003JD003823, 2004.

Mu, M., Randerson, J. T., van der Werf, G. R., Giglio, L., Kasibhatla, P., Morton, D., Collatz, G. J., DeFries, R. S., Hyer, E. J., Prins, E. M., Griffith, D. W. T., Wunch, D., Toon, G. C., Sherlock, V., and Wennberg, P. O.: Daily and 3-hourly variability in global fire emissions and consequences for atmospheric model prediction of carbon monoxide, J. Geophys. Res., 116, D24303, 
doi:10.1029/2011JD016245, 2011.

Park, S. H., Gong, S. L., Gong, W., Makar, P. A., Moran, M. D., Zhang, J., and Stroud, C. A.: Relative impact of windblown dust versus anthropogenic fugitive dust in $\mathrm{PM}_{2.5}$ on air quality in North America, J. Geophys. Res., 115, D16210, doi:10.1029/2009JD013144, 2010.

Peters-Lidard, C. D., Houser, P. R., Tian, Y., Kumar, S. V., Geiger, J., Olden, S., Lighty, L., Doty, B., Dirmeyer, P., Adams, J., Mitchell, K., Wood, E. F., and Sheffield, J.: High-performance Earth system modeling with NASA/GSFC's Land Information System, Innovations in Systems and Software Engineering, 3, 157-165, 2007.

Rodell, M., Houser, P. R., Berg, A. A., and Famiglietti, J. S.: Evaluation of 10 methods for initializing a land surface model, J. Hydrometeorol., 6, 146-155, 2005.

Shi, J. J., Tao, W.-K., Matsui, T., Cifelli, R., Hou, A., Lang, S., Tokay, A., Wang, N.-Y., Peters-Lidard, C., Skofronick-Jackson, G., Rutledge, S., and Petersen, W.: WRF Simulations of the 2022 January 2007 Snow Events over Eastern Canada: Comparison with In Situ and Satellite Observations, J. Appl. Meteorol. Clim., 49, 2246-2266, 2010.

Santanello, J. A., Peters-Lidard, C. D., and Kumar, S. V.: Diagnosing the Sensitivity of Local Land-Atmosphere Coupling via the Soil Moisture-Boundary Layer Interaction, J. Hydrometeorol., 12, 766-786, 2011.

Santanello, J. A., Peters-Lidard, C. D., Kennedy, A., and Kumar, S. V.: Diagnosing the nature of land-atmosphere coupling: A case study of dry/wet extremes in the U.S. Southern Great Plains, J. Hydrometeorol. 14, 3-24, doi:10.1175/JHM-D-12-023.1, 2013.

Seinfeld, J. H. and Pandis, S. N.: Atmospheric Chemistry and Physics - From Air Pollution to Climate Change, 2nd Edn., John Wiley \& Sons, New York, NY, 1326 pp., 2006.

Seneviratne, S. I., Corti, T., Davin, E. L., Hirschi, M., Jaeger, E. B., Lehner, I., Orlowsky, B., and Teuling, A. J.: Investigating soil moisture-climate interactions in a changing climate: A review, Earth-Sci. Rev., 99, 125-161, 2010.

Stockwell, W. R., Middleton, P., Chang, J. S., and Tang, X.: The Second Generation Regional Acid Deposition Model Chemical Mechanism for Regional Air Quality Modeling, J. Geophys. Res., 95, 16343-16367, 1990.
Sun, W.-Y. and Bosilovich, M. G.: Planetary boundary layer and surface layer sensitivity to land surface parameters, Bound.-Lay. Meteorol., 77, 353-378, 1996.

Tao, W.-K., Shi, J. J., Chen, S. S., Lang, S., Lin, P.-L., Hong, S.Y., Peters-Lidard, C., and Hou, A.: The impact of microphysical schemes on hurricane intensity and track, Asia-Pacific, J. Atmos. Sci., 47, 1-16, 2011.

Tao, Z., Larson, S. M., Wuebbles, D. J., Williams, A., and Caughey, M.: A summer simulation of biogenic contributions to groundlevel ozone over the continental United State, J. Geophys. Res., 108, 4404, doi:10.1029/2002JD002945, 2003.

USEPA: Guideline for regulatory applications of the Urban Airshed Model. US Environmental Protection Agency Report EPA450/4-91-013, Office of Air Quality Planning and Standards, Research Triangle Park, NC, 89 pp., 1991.

van der Werf, G. R., Randerson, J. T., Giglio, L., Collatz, G. J., Mu, M., Kasibhatla, P. S., Morton, D. C., DeFries, R. S., Jin, Y., and van Leeuwen, T. T.: Global fire emissions and the contribution of deforestation, savanna, forest, agricultural, and peat fires (19972009), Atmos. Chem. Phys., 10, 11707-11735, doi:10.5194/acp10-11707-2010, 2010.

Vanvyve, E., Hall, N., Messager, C., Leroux, S., and van Ypersele, J.-P.: Internal variability in a regional climate model over West Africa, Clim. Dynam., 30, 191-202, doi:10.1007/s00382-0070281-6, 2008.

Williams, E. J., Guenther, A. B., and Fehsenfeld, F. C.: An inventory of nitric oxide from soils in the United States, J. Geophys. Res. 97, 511-519, 1992.

Wu, S., Mickley, L. J., Kaplan, J. O., and Jacob, D. J.: Impacts of changes in land use and land cover on atmospheric chemistry and air quality over the 21st century, Atmos. Chem. Phys., 12, 1597-1609, doi:10.5194/acp-12-1597-2012, 2012.

Xu, Y., Wesely, M. L., and Pierce, T. E.: Estimates of biogenic emissions using satellite observations and influence of isoprene emission on $\mathrm{O}_{3}$ formation over the eastern United States, Atmos. Environ., 36, 5819-5829, 2002. 